\title{
Biofuels Production through Biomass Pyrolysis -A Technological Review
}

\author{
Mohammad I. Jahirul ${ }^{1,2}$, Mohammad G. Rasul ${ }^{1, *}$, Ashfaque Ahmed Chowdhury ${ }^{1}$ and \\ Nanjappa Ashwath ${ }^{1}$
}

1 Centre for Plant and Water Science, Central Queensland University, Rockhampton, Queensland 4702, Australia; E-Mails: md_jahirul@yahoo.com (M.I.J.); A.Chowdhury@cqu.edu.au (A.A.C.); n.ashwath@cqu.edu.au (N.A.)

2 Faculty of Science and Technology, School of Chemistry, Physics and Mechanical Engineering, Queensland University of Technology, Brisbane, Queensland 4000, Australia;

E-Mail:m1.islam@qut.edu.au

* Author to whom correspondence should be addressed; E-Mail: m.rasul@cqu.edu.au;

Tel.:+61-749309676.

Received: 10 October 2012; in revised form: 13 November 2012 / Accepted: 14 November 2012 / Published: 23 November 2012

\begin{abstract}
There has been an enormous amount of research in recent years in the area of thermo-chemical conversion of biomass into bio-fuels (bio-oil, bio-char and bio-gas) through pyrolysis technology due to its several socio-economic advantages as well as the fact it is an efficient conversion method compared to other thermo-chemical conversion technologies. However, this technology is not yet fully developed with respect to its commercial applications. In this study, more than two hundred publications are reviewed, discussed and summarized, with the emphasis being placed on the current status of pyrolysis technology and its potential for commercial applications for bio-fuel production. Aspects of pyrolysis technology such as pyrolysis principles, biomass sources and characteristics, types of pyrolysis, pyrolysis reactor design, pyrolysis products and their characteristics and economics of bio-fuel production are presented. It is found from this study that conversion of biomass to bio-fuel has to overcome challenges such as understanding the trade-off between the size of the pyrolysis plant and feedstock, improvement of the reliability of pyrolysis reactors and processes to become viable for commercial applications. Further study is required to achieve a better understanding of the economics of biomass pyrolysis for bio-fuel production, as well as resolving issues related to the capabilities of this technology in practical application.
\end{abstract}


Keywords: biomass pyrolysis; bio-fuel production; biomass feedstock; pyrolysis reactor; economics of pyrolysis process

\section{Introduction}

Biomass is a promising eco-friendly alternative source of renewable energy in the context of current energy scenarios. Current global energy supply is to a large extent based on fossil fuels (oil, natural gas, coal), of which the reserves are finite. Given the growing world population, the increasing energy consumption per capita and the evidence of global warming, the necessity for long-term alternative energy sources is obvious. For these twin crises of fossil fuel depletion and environmental degradation, energy planning and technology improvement has become an important public agenda of most developed and developing countries. In order to counter greenhouse gas emissions, the European Union ratified the Kyoto Protocol and emphasized the potential for scientific innovation in 2002, but unfortunately there has been a failure to meet the agreed targets. As a consequence, the global warming situation is likely to be increasing day by day. Atmospheric $\mathrm{CO}_{2}$ has already exceeded the dangerous level 10 years earlier than had previously been predicted. The award of the 2007 Nobel Peace Prize to the Intergovernmental Panel on Climate Change (IPCC) and to Al Gore establishes the importance of climate change issue. Current Australian Government has a long term target of a $60 \%$ reduction in emission relative to 1990 by 2050 [1]. All of these concerns have boosted the importance of research for alternatives to fossil derived products.

Biomass is recognized as a renewable resource for energy production and is abundantly available around the world [2]. Biomass utilization in mainstream energy uses is receiving great attention due to environmental considerations and the increasing demands of energy worldwide [3]. Although complex in nature, biomass contains a small amount of sulphur, nitrogen and ash. Therefore, combustion of bio-fuel produces less harmful gas emissions such as nitrogen oxides $\left(\mathrm{NO}_{x}\right)$, sulphur dioxide $\left(\mathrm{SO}_{2}\right)$ and soot compared to conventional fossil fuels. In addition, zero or negative carbon dioxide $\left(\mathrm{CO}_{2}\right)$ emission is possible from biomass fuel combustion because released $\mathrm{CO}_{2}$ from the combustion of bio-oil can be recycled into the plant by photosynthesis [4].

Biomass can be converted to bio-fuel via different thermal, biological and physical processes. Among the biomass to energy conversion processes, pyrolysis has attracted more interest in producing liquid fuel product because of its advantages in storage, transport and versatility in application such as combustion engines, boilers, turbines, etc. In addition, solid biomass and waste are very difficult and costly to manage which also gives impetus to pyrolysis research. However it is still at an early stage in development and needs to overcome a number of technical and economic barriers to compete with traditional fossil fuel based techniques [5,6]. The production of bio-liquids and other products (char and gas) by pyrolysis of different biomass species has been extensively investigated in the past. Some of these biomass species include beech wood [7], bagasse [8] woody biomass [9,10], straws [11], seedcakes [12] and municipal solid waste (MSW) [13,14].

Pyrolysis is the thermal decomposition of biomass occurring in the absence of oxygen. The word is derived from the Greek words "pyro" meaning fire and "lysis" meaning decomposition or breaking 
down into constituent parts. More than 5500 years ago in Southern Europe and the Middle East, pyrolysis technology was used for charcoal production [15]. Pyrolysis has also been used to produce tar for caulking boats and certain embalming agents in ancient Egyptian [16]. Since then, use of pyrolysis processes has been increasing and is widely used for charcoal and coke production. This is because only the burning of charcoal allowed the necessary temperatures to be reached to melt tin with copper to produce bronze.

Pyrolysis technology has the capability to produce bio-fuel with high fuel-to-feed ratios. Therefore, pyrolysis has been receiving more attention as an efficient method in converting biomass into bio-fuel during recent decades [17]. The ultimate goal of this technology is to produce high-value bio-oil for competing with and eventually replacing non-renewable fossil fuels. However, the development of advanced technologies is the next challenge for pyrolysis researchers to achieve this target. It is necessary to convert biomass into liquid fuels for direct use in vehicles, trains, ships and aeroplanes to replace petrol and diesel [18-20]. Further development of pyrolysis technology is ongoing and many research articles have been published on the pyrolysis concept in bio-oil applications in recent times. In this paper, over 200 publications are reviewed and discussed. The current status and development of this technology is presented.

\section{Pyrolysis Principles}

Biomass is one of the first sources of energy used by mankind. It is still the major source of energy in developing countries. In the western world, a renewed interest in biomass started in the nineteen-seventies. Charcoal, which is a smokeless fuel used for heating purpose, has been produced from wood biomass for thousands of years. Its first technological use can be dated back to the Iron Age when charcoal was used in ore melting to produce iron. The disadvantages of early pyrolysis technology include slow production, low energy yield and excessive air pollution. Therefore, technology development to recover the maximum possible energy from a particular type of biomass is continuing as an important step towards a profitable investment. Nowadays there are mainly three ways frequently used to extract energy from biomass. These are: combustion (exothermic), gasification (exothermic) and pyrolysis (endothermic) [21]. Combustion is the oxidation of fuel in which biomass can be completely oxidized and transferred into heat. However, efficiency of this process is only about $10 \%$ and this manner of use is a source of substantial pollution [22,23]. Gasification is a partly oxidizing process that converts a solid fuel into a gaseous fuel, while pyrolysis is the first stage of both combustion and gasification processes [24]. Therefore pyrolysis is not only an independent conversion technology, but also a part of gasification and combustion [25], which consists of a thermal degradation of the initial solid fuel into gases and liquids without an oxidizing agent.

The process of pyrolysis of organic matter is very complex and consists of both simultaneous and successive reactions when organic material is heated in a non-reactive atmosphere. In this process; thermal decomposition of organic components in biomass starts at $350{ }^{\circ} \mathrm{C}-550{ }^{\circ} \mathrm{C}$ and goes up to $700{ }^{\circ} \mathrm{C}-800{ }^{\circ} \mathrm{C}$ in the absence of air/oxygen [26]. The long chains of carbon, hydrogen and oxygen compounds in biomass break down into smaller molecules in the form of gases, condensable vapours (tars and oils) and solid charcoal under pyrolysis conditions. Rate and extent of decomposition of each 
of these components depends on the process parameters of the reactor (pyrolysis) temperature; biomass heating rate; pressure; reactor configuration; feedstock; etc.

Figure 1 shows possible reaction pathways for the pyrolysis of wood biomass. These include three lumped product categories, starting with a first order reaction. Lanzetta and Blasi found that, at the beginning of the pyrolysis $\left(250{ }^{\circ} \mathrm{C}-300{ }^{\circ} \mathrm{C}\right)$ process, most of the volatiles are released at a rate 10 times faster than the next step [27].

Relative proportions of the end products after pyrolysis of biomass at a range of temperatures are shown in Figure 2. However, pyrolysis processes cannot be limited to a single reaction path because of widely varying structure and compositional properties of biomass [28].

Figure 1. Representation of the reaction paths for wood pyrolysis [29].

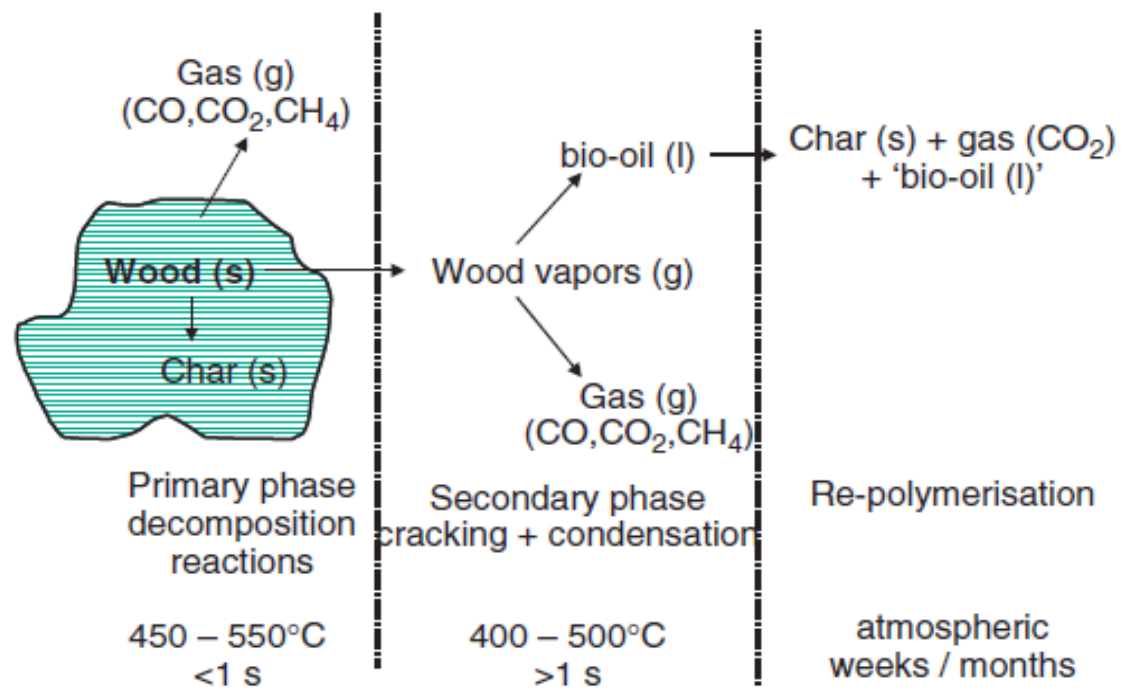

Figure 2. Relative proportions of end products in pyrolysis of biomass [30].

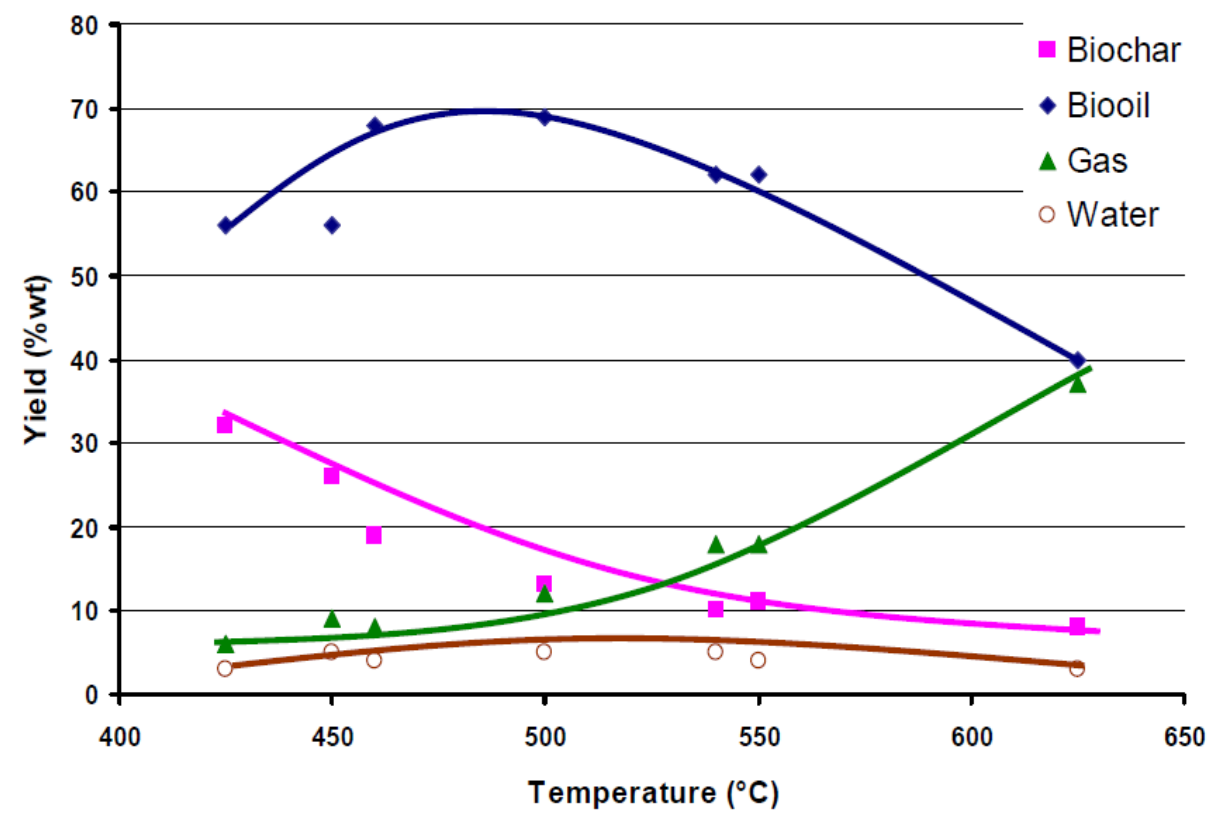




\section{Pyrolysis Classification}

Depending on the operating condition, pyrolysis can be classified into three main categories: conventional, fast and flash pyrolysis. These differ in process temperature, heating rate, solid residence time, biomass particle size, etc. However, relative distribution of products is dependent on pyrolysis type and pyrolysis operating parameters as shown in Table 1. In addition, different types of pyrolysis processes are described in the following three sub-sections.

Table 1. Typical operating parameters and products for pyrolysis process [31,32].

\begin{tabular}{lccccccc}
\hline Pyrolysis & Solid Residence & Heating & Particle & \multirow{2}{*}{ Temp. (K) } & \multicolumn{2}{c}{ Product Yield (\%) } \\
\cline { 5 - 8 } Process & Time (s) & Rate $(\mathbf{K} / \mathbf{s})$ & Size $(\mathbf{m m})$ & & Oil & Char & Gas \\
\hline Slow & $450-550$ & $0.1-1$ & $5-50$ & $550-950$ & 30 & 35 & 35 \\
Fast & $0.5-10$ & $10-200$ & $<1$ & $850-1250$ & 50 & 20 & 30 \\
Flash & $<0.5$ & $>1000$ & $<0.2$ & $1050-1300$ & 75 & 12 & 13 \\
\hline
\end{tabular}

\subsection{Slow Pyrolysis}

Slow pyrolysis has been used for thousands of years to enhance char production at low temperatures and low heating rates. In this process, the vapour residence time is too high ( $5 \mathrm{~min}$ to $30 \mathrm{~min}$ ) and components in the vapour phase continue to react with each other which results in the formation of solid char and other liquids [33]. However, slow pyrolysis has some technological limitations which made it unlikely to be suitable for good quality bio-oil production. Cracking of the primary product in the slow pyrolysis process occurs due to high residence time and could adversely affect bio-oil yield and quality. Moreover, long residence time and low heat transfer demands extra energy input [34,35].

\subsection{Fast Pyrolysis}

In the fast pyrolysis process, biomass is rapidly heated to a high temperature in the absence of oxygen. Typically on a weight basis, fast pyrolysis produces $60 \%-75 \%$ of oily products (oil and other liquids) with $15 \%-25 \%$ of solids (mainly biochar) and $10 \%-20 \%$ of gaseous phase depending on the feedstock used. The production of liquids is usually yielded from biomass in a low temperature, high heating rate and short resident time environment. The basic characteristics of the fast pyrolysis process are high heat transfer and heating rate, very short vapour residence time, rapid cooling of vapours and aerosol for high bio-oil yield and precision control of reaction temperature [36].

Fast-pyrolysis technology is receiving incredible popularity in producing liquid fuels and a range of speciality and commodity chemicals. This liquid product can be easily and economically transported and stored, thereby de-coupling the handling of solid biomass from utilization [37]. It also has potential to supply a number of valuable chemicals that offer the attraction of much higher added value than fuels. Fast pyrolysis technology can have relatively low investment costs and high energy efficiencies compared to other processes, especially on a small scale. Production of bio-oil through fast pyrolysis has received more attention in recent year due to the following potential advantages [29,38,39]: 
- Renewable fuel for boiler, engine, turbine, power generation and industrial processes;

- Low cost and neutral $\mathrm{CO}_{2}$ balance;

- Utilisation of second generation bio-oil feed stocks and waste materials (forest residue, municipal and industrial waste, etc.);

- Storability and transportability of liquid fuels;

- High energy density compared to atmospheric biomass gasification fuel gases;

- Possibility for separating minerals on the site of liquid fuel production to be recycled to the soil as a nutrient;

- Secondary conversion to motor-fuels, additives or special chemicals;

- Primary separation of the sugar and lignin fractions in biomass with subsequent further upgrading.

\subsection{Flash Pyrolysis}

The flash pyrolysis of biomass is a promising process for the production of solid, liquid and gaseous fuel from biomass which can achieve up to $75 \%$ of bio-oil yield [40]. This process can be characterized by rapid devolatilization in an inert atmosphere, high heating rate of the particles, high reaction temperatures between $450{ }^{\circ} \mathrm{C}$ and $1000{ }^{\circ} \mathrm{C}$ and very short gas residence time (less than $1 \mathrm{~s})$ [41]. However this process has some technological limitations, for instance: poor thermal stability and corrosiveness of the oil, solids in the oil, Increase of the viscosity over time by catalytic action of char, alkali concentrated in the char dissolves in the oil and production of pyrolytic water [42].

\section{Biomass Feedstock}

Biomass energy is the one the earliest and now the third largest global source of energy, comprising up to $40 \%-50 \%$ of energy usage in many developing countries that have large agriculture and forest areas [43]. Biomass is used to meet a variety of energy needs, including generating electricity, heating homes and providing process heat for industrial facilities. Goyal et al. define biomass as any living matter on earth. More specifically, biomass can be defined as material derived from growing plants or from animal manure which mainly consists of carbon, hydrogen, oxygen, nitrogen and smaller portions of inorganic species [44]. A typical analysis of dry wood yields components is carbon $52.42 \%$, oxygen $6.35 \%$, hydrogen $40.83 \%$ and nitrogen $0.4 \%$.

Biomass can be directly or indirectly produced by green plants converting sunlight into plant material through photosynthesis [45]. The solar energy driving photosynthesis is stored in the chemical bonds of the structural components of biomass which is a natural process. During combustion, biomass releases this energy in the form of heat. For that reason, biomass species are considered as renewable sources of energy which do not add carbon dioxide to the environment, in contrast to non-renewable fossil fuels. In addition, the unique feature of biomass is that it is the only renewable energy source which can be converted into convenient solid, liquid and gaseous fuels [46]. In the following sub-section different components of biomass are described. Physical and chemical properties of different biomass species are shown in Tables 2 and 3, respectively. The high heating value (HHV) of the raw biomass and pyrolysis products are calculated by means of the following Institute of Gas 
Technology (IGT) formula shown in Equation (1) [47]. The amounts of the elements (C, H, O, N and ash) are expressed in mass percentages:

$$
H H V\left(\frac{k J}{k g}\right)=354.68 \mathrm{C}+1376.29 \mathrm{H}-15.92 \mathrm{Ash}-124.69(\mathrm{O}+\mathrm{N})+71.26
$$

\subsection{Composition of Biomass}

The major components of biomass are cellulose, hemicellulose and lignin, each of which is different in their decomposition behaviour (Table 2). Moreover, decomposition of each component depends on heating rate, temperature and the presence of contaminants due to different molecular structures $[48,49]$. In the pyrolysis process, the three components are not decomposed at the same time as shown in Figure 3. Hemicellulose would be the easiest one to be pyrolysised, next would be cellulose, while lignin would be the most difficult one. Interestingly, both lignin and hemicellulose could affect the pyrolysis characteristics of cellulose while they could not affect each other obviously in the pyrolysis process [50]. Yang et al. observed that bio-oil mainly derived from the cellulose component of biomass (around $500{ }^{\circ} \mathrm{C}$ ), whereas the solid residue (bio-char) came from the lignin [51]. This is also evident from the composition of bio-char, which has an element composition close to that of lignin [29]. Therefore, pyrolysis of biomass with a high percentage of lignin can produce better bio-oil yields. This is because of the different physio-chemical characteristics of cellulose, hemicellulose and lignin.

Table 2. Lignin, cellulose and hemicellulose content of selected biomass [52-57].

\begin{tabular}{llll}
\hline Feedstock & Lignin (\%) & Cellulose (\%) & Hemicellulose (\%) \\
\hline Wood & $25-30$ & $35-50$ & $20-30$ \\
Wheat straw & $15-20$ & $33-40$ & $20-25$ \\
Switch grass & $5-20$ & $30-50$ & $10-40$ \\
Sugarcane bagasse & $23-32$ & $19-24$ & $32-48$ \\
Miscanthus & 17 & 24 & 44 \\
Corn stover & $16-21$ & 28 & 35 \\
Hazelnut shell & 42.9 & 28.8 & 30.4 \\
Olive husk & 48.4 & 24 & 23.6 \\
Corncob & 15 & 50.5 & 31 \\
Tea waste & 40 & 30.20 & 19.9 \\
Walnut shell & 52.3 & 25.6 & 22.7 \\
Almond shell & 20.4 & 50.7 & 28.9 \\
Sunflower shell & 17 & 48.4 & 34.6 \\
Nut Shell & $30-40$ & $25-30$ & $25-30$ \\
Paper & $0-15$ & $85-99$ & 0 \\
Rice straw & 18 & 32.1 & 24 \\
Stored refuse & 20 & 60 & 20 \\
Leaves & 0 & $15-20$ & $80-85$ \\
Cotton seed hairs & 0 & $80-95$ & $5-20$ \\
\hline
\end{tabular}


Table 2. Cont.

\begin{tabular}{llll}
\hline Feedstock & Lignin (\%) & Cellulose (\%) & Hemicellulose (\%) \\
\hline Industrial waste paper & $5-10$ & $60-70$ & $10-20$ \\
Barley straw & $14-15$ & $31-34$ & $24-29$ \\
Oat straw & $16-19$ & $31-37$ & $24-29$ \\
Bamboo & $21-31$ & $26-43$ & $15-26$ \\
Rye straw & $16-19$ & $33-35$ & $27-30$ \\
Coastal Bermuda grass & 6.4 & 25 & 35.7 \\
Jute fibre & $21-26$ & $45-53$ & $18-21$ \\
Banana waste & 14 & 13.2 & 14.8 \\
\hline
\end{tabular}

Figure 3. Decomposition rate of individual biomass components with pyrolysis temperature [58].

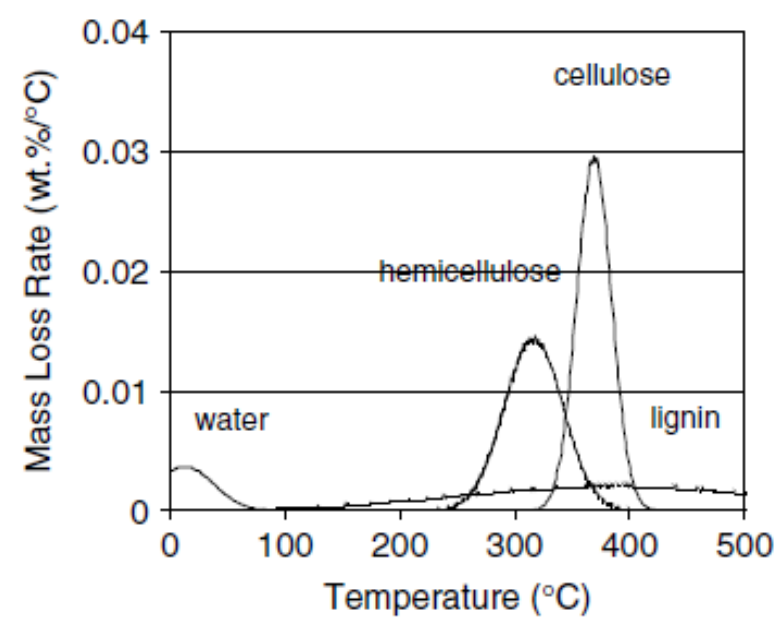

\subsection{Physical and Chemical Characteristics of Biomass}

Although the feedstock used for pyrolysis is more important, little is known about the optimal feedstock constituents for energy production. This is because the current commercial and research-scale pyrolysis plants are dedicated to specific waste streams, giving little attention to optimise the constituents. However, some recent studies $[59,60]$ have focused on a wide range of biomass feedstock in pyrolysis applications. Feed stocks with high lignin content produce the highest bio-char yields when pyrolyzed at moderate temperatures (approx. $500{ }^{\circ} \mathrm{C}$ ). In addition, the ratios of volatile matter, fixed carbon, ash content and moisture are also indicators of pyrolysis product yields. In general biomass with high volatile matter produces high quantities of bio-oil and syngas, whereas fixed carbon increases the bio-char production. Moisture content in biomass has an influence in the heat transfer process with significant effects on product distribution [61]. It has been observed that an increase in moisture content results in increased liquid product yield while the solid and gas yields decrease [62]. This is because moisture produces large quantities of condensate water in liquid phase [63]. Therefore, biomass such as walnut shell, olive husk and hazelnut shell is more favourable in bio-char production (which is related to the lignin content) as shown in Table 2. The elemental ratio of carbon, oxygen, hydrogen, nitrogen and ash content, listed in Table 4, also has an important effect on pyrolysis products. Friedl et al. found that feed stocks with low mineral and nitrogen contents are 
favoured for bio-oil and syngas production [64]. These include wood and biomass from energy crops, woody plants, high productivity grasses and low-cost agricultural by-products, including cereal straw.

Table 3. Physical properties of selected biomass feedstock $[45,48,54,55,65,66]$.

\begin{tabular}{llllll}
\hline Feedstock & $\begin{array}{l}\text { Density } \\
\left(\mathbf{K g} / \mathbf{m}^{\mathbf{3}}\right)\end{array}$ & $\begin{array}{l}\text { Moisture } \\
\text { Content } \mathbf{( \% )}\end{array}$ & $\begin{array}{l}\text { Ash Content } \\
\mathbf{( \% )}\end{array}$ & $\begin{array}{l}\text { Volatile } \\
\text { Matter (\%) }\end{array}$ & $\begin{array}{l}\text { Fixed } \\
\text { Carbon (\%) }\end{array}$ \\
\hline Wood & 1186 & 20 & $0.4-1$ & 82 & 17 \\
Bituminous coal & & 11 & $8-11$ & 35 & 45 \\
Hybrid polar & 150 & 45 & $0.5-2$ & - & - \\
Switchgrass & 108 & $13-15$ & $4.5-5.8$ & - & - \\
Miscanthus & $70-100$ & 11.5 & $1.5-4.5$ & 66.8 & 15.9 \\
Sugarcane baggage & 1198 & & $3.2-5.5$ & - & - \\
Barley strew & 210 & 30 & 6 & 46 & 18 \\
Wheat straw & 1233 & 16 & 4 & 59 & 21 \\
Danish pine & & 8 & 1.6 & 71.6 & 19 \\
Rice straw & 200 & 6 & 4.3 & 79 & 10.7 \\
Fire wood & - & 7.74 & 1.98 & 80.86 & 17.16 \\
Grateloupia filicina & - & 4.93 & 22.37 & 55.93 & 17.01 \\
Birch & 125 & 18.9 & 0.004 & - & 20 \\
Pine & 124 & 17 & 0.03 & - & 16 \\
Polar & 120 & 16.8 & 0.007 & - & - \\
\hline
\end{tabular}

Table 4. Chemical characteristics of some selected biomass materials $[48,55,66]$.

\begin{tabular}{llllll}
\hline Feedstock & $\begin{array}{l}\text { Carbon } \\
\text { (\%) }\end{array}$ & $\begin{array}{l}\text { Hydrogen } \\
\mathbf{( \% )}\end{array}$ & $\begin{array}{l}\text { Oxygen } \\
\mathbf{( \% )}\end{array}$ & $\begin{array}{l}\text { Nitrogen } \\
\mathbf{( \% )}\end{array}$ & $\begin{array}{l}\text { Ash } \\
\mathbf{( \% )}\end{array}$ \\
\hline Wood & 51.6 & 6.3 & 41.5 & 0.1 & 1 \\
Cypress & 55 & 6.5 & 38.1 & - & 0.4 \\
Olive baggage & 66.9 & 9.2 & 21.9 & 2 & - \\
Wheat straw & 48.5 & 5.5 & 3.9 & 0.3 & 4 \\
Barley straw & 45.7 & 6.1 & 38.3 & 0.4 & 6 \\
Bituminous coal & 73.1 & 5.5 & 8.7 & 1.4 & 9 \\
Scots & 56.4 & 6.3 & - & 0.1 & 0.09 \\
Birch & 44 & 6.9 & 49 & 0.1 & .004 \\
Pine & 45.7 & 7 & 47 & 0.1 & 0.03 \\
Polar & 48.1 & 5.30 & 46.10 & 0.14 & 0.007 \\
Willow & 47.78 & 5.90 & 46.10 & 0.31 & 1.30 \\
Switchgrass & 44.77 & 5.79 & 49.13 & 0.31 & 4.30 \\
Reed canary grass & 45.36 & 5.81 & 48.49 & 0.34 & 5.10 \\
Dactylis lomarata & 42.96 & 5.70 & 49.44 & 1.90 & 7.50 \\
Festuca arundinacea & 42.22 & 5.64 & 50.65 & 1.50 & 7.30 \\
Lolium perenne & 43.12 & 5.80 & 49.80 & 1.28 & 6.20 \\
\hline
\end{tabular}




\section{Pyrolysis Reactor}

The reactor is the heart of any pyrolysis process. Reactors have been the subject of considerable research, innovation and development to improve the essential characteristics of high heating rates, moderate temperatures and short vapour product residence times for liquids. At first, pyrolysis reactor developers had assumed that small biomass particles size (less than $1 \mathrm{~mm}$ ) and very short residence time would achieve high bio-oil yield, however later research has found different results. Particle size and vapour residence time have little effect on bio-oil yield, whereas those parameters greatly affect bio-oil composition $[66,67]$. With the continuation of pyrolysis technology development, a number of reactor designs have been explored to optimize the pyrolysis performance and to produce high quality bio-oil. However, each reactor type has specific characteristics, bio-oil yielding capacity, advantages and limitations. Of the various reactor designs, the most popular types are described in the following sub-sections.

\subsection{Fixed Bed Reactor}

The fixed bed pyrolysis system consists of a reactor with a gas cooling and cleaning system. The technology of the fixed bed reactor is simple, reliable and proven for fuels that are relatively uniform in size and have a low content of fines [68]. In this type of reactor, the solids move down a vertical shaft and contact a counter-current upward moving product gas stream. Typically, a fixed bed reactor is made up of firebricks, steel or concrete with a fuel feeding unit, an ash removal unit and a gas exit. The fixed bed reactors generally operate with high carbon conservation, long solid residence time, low gas velocity and low ash carry over [69,70]. These types of reactor are being considered for small scale heat and power applications. The cooling system and gas cleaning consists of filtration through cyclone, wet scrubbers and dry filters $[71,72]$. The major problem of fixed bed reactors is tar removal; however recent progress in thermal and catalytic conversion of tar has given viable options for removing tar $[51,73,74]$.

\subsection{Fluidized-Bed Reactor}

The fluidized-bed reactor consists of a fluid-solid mixture that exhibits fluid like properties. This is generally achieved by the introduction of pressurized fluid through the solid particulate substance. Fluidized-bed reactors appear to be popular for fast pyrolysis as they provide rapid heat transfer, good control for pyrolysis reaction and vapour residence time, extensive high surface area contact between fluid and solid per unit bed volume, good thermal transport inside the system and high relative velocity between the fluid and solid phase [75]. Different types of fluidized-bed reactors are described below.

\subsubsection{Bubbling Fluidized-Bed Reactors}

Bubbling fluidized-beds are simple to construct and operate. They provide better temperature control, solids-to-gas contact, heat transfer and storage capacity because of the high solids density in the bed. Heated sand is used as the solid phase of the bed which rapidly heats the biomass in a non-oxygen environment, where it is decomposed into char, vapour, gas and aerosols. The fluidizing gas stream conveys the decomposed biomass constituents produced out of the reactor as shown in 
Figure 4 [76]. After the pyrolytic reaction, the charcoal is removed by a cyclone separator and stored. The remaining vapour is then rapidly cooled with a quenching system, condensed into bio-oil and stored. Bubbling fluidized-bed pyrolysis is very popular because it produces high quality bio-oil and liquid yield is about $70 \%-75 \%$ weight of the biomass on a dry basis. Char does not accumulate in the fluidized bed, but it is rapidly separated. The residence time of solids and vapour is controlled by the fluidising flow rate. One important feature of bubbling fluidizing bed reactors is that they need small biomass particle sizes (less than $2-3 \mathrm{~mm}$ ) to achieve high biomass heating rates.

Figure 4. Bubbling fluidized-bed reactor [76].

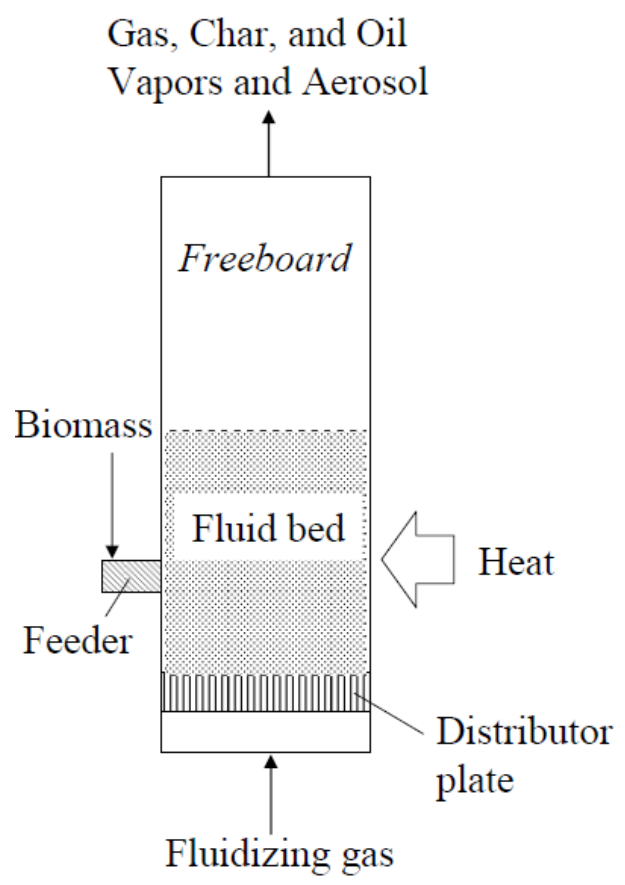

\subsubsection{Circulating Fluidized-Bed Reactors}

Circulating fluidized-beds have similar features to bubbling fluidized-bed reactors except shorter residence times for chars and vapours. This results in higher gas velocity and char content in bio-oil than in bubbling fluidized bed reactors. One advantage is that this type of reactor is suitable for very large throughputs, even though the hydrodynamics are more complex [77]. There are generally two types of circulating fluidized bed reactors: single circulating (Figure 5) and double circulating (Figure 6).

\subsection{Ablative Reactor}

Ablative pyrolysis is fundamentally different from fluid bed processes with the mode of heat transfer being through a molten layer at the hot reactor surface and the absence of a fluidizing gas. Mechanical pressure is used to press biomass against a heated reactor wall. Material in contact with the wall essentially "melts" and, as it is moved away, the residual oil evaporates as pyrolysis vapours [78]. Advantages of ablative reactors are that feed material does not require excessive grinding, and the process allows much larger biomass particle size than other types of pyrolysis reactors. These types of reactor can use particle sizes up to $20 \mathrm{~mm}$ in contrast to the $2 \mathrm{~mm}$ particle size required for fluidized 
bed designs. On the other hand, this configuration is slightly more complex due to mechanical nature of the process. Scaling is a linear function of the heat transfer as this system is surface area controlled. Therefore ablative reactors do not benefit from the same economies of scale as the other reactor types [32]. The commonly used ablative reactor types are ablative vortex and ablative rotating disk, which are described in the following paragraphs.

\subsubsection{Vortex Reactor}

In a vortex ablative pyrolysis reactor, biomass particles are entrained in a hot inert gas (steam or nitrogen) flow and then enter into the reactor tube tangentially. Biomass particles are then forced to slide on the reactor wall at high velocity by means of high centrifugal forces. The particles are melted on the hot reactor wall which is maintained at a temperature of about $625{ }^{\circ} \mathrm{C}$ and leave a liquid film of bio-oil. Unconverted particles are recycled with a special solids recycle loop [79]. Vapours generated on the reactor wall are quickly swept out by carrier gases in 50-100 milliseconds. This design is able to meet the requirements of fast pyrolysis and has demonstrated a bio-oil yield of $65 \%$.

\subsubsection{Rotating Disk Reactor}

In the rotating plate reactor, biomass feed stocks are forced to slide on a hot rotating disk. While under pressure and heat transfer from the hot surface, biomasses soften and vaporize in contact with the rotating disk which causes the pyrolysis reaction. The most important feature of this reactor is that there is no inert gas medium required, thus resulting in smaller processing equipment. But this process is dependent on the surface area, and hence scaling can be an issue for larger facilities [76].

\subsection{Vacuum Pyrolysis Reactor}

Vacuum reactors perform a slow pyrolysis process with lower heat transfer rates which results in lower bio-oil yields of $35 \%-50 \%$ compared to the $75 \mathrm{wt} \%$ reported with the fluidized bed technologies. The pyrolysis process in vacuum reactor is very complicated mechanically and requires high investment and maintenance costs. A moving metal belt conveys biomass into the high temperature vacuum chamber. On the belt, biomasses are periodically stirred by a mechanical agitator. A burner and an induction heater are used with molten salts as a heat carrier to heat the biomass [80]. Because of operating in a vacuum, these types of pyrolysis reactors require special solids feeding and discharging devices to maintain a good seal at all times. The main benefit of vacuum reactors is that they can process larger sized biomass particles (up to $2-5 \mathrm{~cm}$ ) than fluidized bed reactors.

\subsection{Rotating Cone Reactor}

Intense mixing of biomass and hot inert particles is the most effective way to transfer heat to biomass in the pyrolysis process. However fluidised bed mixing requires too much ineffective inert gas. In the rotating cone reactor the pyrolysis reaction takes place upon mechanical mixing of biomass and hot sand, instead of using inert gas. The biomass feedstock and sand are introduced at the base of the cone while spinning causes centrifugal force to move the solids upward to the lip of the cone. As the solids spill over the lip of the cone, pyrolysis vapours are directed to a condenser. The char and 
sand are sent to a combustor where the sand gets re-heated before again being introduced at the base of the cone with the fresh biomass feedstock. Although the design of the rotating cone reactor is complex, it demonstrates high bio-oil yield [81]. Two million tons per day plant operating on palm oil empty fruit bunches was commissioned in Malaysia in 2006 [78].

\subsection{PyRos Reactor}

PyRos pyrolysis is implemented in a cyclonic reactor with an integrated hot gas filter (the rotational particle separator) in one unit to produce particle free bio-oil. The biomass and the inert heat carrier are introduced as particles into the cyclone and the solids are transported by recycled vapours from the process. By centrifugal force the particles are moved downwards to the periphery of the cyclone. During the transport downwards in the reactor, the biomass particles are dried, heated up and devolatilized. The average process temperature is $450{ }^{\circ} \mathrm{C}-550{ }^{\circ} \mathrm{C}$. The typical gas residence time in the reactor is 0.5 to $1 \mathrm{~s}$, so secondary cracking reactions of tars in the reactor can be reduced. Evolved vapours are transported rapidly to the centre of the cyclone and leave the cyclone via the rotating filter. The remaining gases and char can be used to heat up the heat carrier and transportation gas. This reactor is comparatively compact and low cost, with $70 \%-75 \%$ bio-oil yield capability [82].

\subsection{Auger Reactor}

In this type of reactor, augers are used to move biomass feedstock through an oxygen free cylindrical heated tube. A passage through the tube raises the feedstock to the desired pyrolysis temperature ranging from $400{ }^{\circ} \mathrm{C}$ to $800{ }^{\circ} \mathrm{C}$ which causes it to devolatilize and gasify. Char is produced and gases are condensed as bio-oil, with non-condensable vapour collected as bio-gas. In this design the vapour residence time can be modified by changing the heated zone through which vapour passes prior to entering the condenser train [16].

\subsection{Plasma Reactor}

The plasma pyrolysis reactors are usually made with a cylindrical quartz tube surrounded by two copper electrodes. Biomass particles are fed at the middle of the tube using a variable-speed screw feeder located on the top of the tube. Electrodes are coupled with electrical power sources to produce thermal energy to gas flows through the tube. Oxygen is removed by an inert gas incorporated in the reactor. This inert gas also serves as working gas to produce plasma. The pyrolysis product vapours are evacuated from the reactor by means of a variable speed vacuum pump [83].

Although consuming high electrical power and having high operating costs, plasma reactors offer some unique advantages in biomass pyrolysis compared with conventional reactors. The high energy density and temperature produced in plasma pyrolysis corresponds with a fast reaction which provides a potential solution for the problems that occur in slow pyrolysis such as the generation of heavy tarry compounds and low productivity of syngas $[48,84]$. In this type of reactor, tar formation is eliminated due to the cracking effects of the highly active plasma environment with a variety electron, ion, atom and activated molecule species [83]. However, a significant proportion of heat from the thermal plasma is released to the surrounding environment by means of radiation and conduction. 


\subsection{Microwave Reactor}

The microwave reactor is one of the recent research focuses in pyrolysis application in which energy transfer occurs through the interaction of molecules or atoms using a microwave-heated bed. The drying and pyrolysis processes of biomass are carried out in a microwave cavity oven powered by electricity. Inert gas is flowing continuously through the reactor to create an oxygen free atmosphere and to serve as the carrier gas as well. Microwave reactors offer several advantages over slow pyrolysis systems which make them an effective method of recovering useful chemicals from biomass. These advantages include efficient heat transfer, exponential control of the heating process and an enhanced chemical reactivity that reduces the formation of undesirable species. Additionally, unexpected physical behaviours such as "hot spots" are appearing in microwave reactors which increases syngas yield [85]. Therefore a wide range of biomasses and industrial wastes are possible to process in microwave reactors with high yields of desirable products such as syngas and bio-oil [86]. The biomasses that are subjected to pyrolysis using microwave reactors include sewage sludges [85,87], coffee hulls [88], glycerol [89]), rice straw [90], corn stalk [91], automotive waste oil [86], wood blocks and wood sawdust [92].

\subsection{Solar Reactor}

The use of solar reactors in pyrolysis provides a suitable means of storing solar energy in the form of chemical energy. This type of reactor is usually made with a quartz tube which has opaque external walls exposed to concentrated solar radiation. A parabolic solar concentrator is attached with the reactor to concentrate the solar radiation. The concentrated solar radiation is capable of generating high temperatures $\left(>700{ }^{\circ} \mathrm{C}\right)$ in the reactor for pyrolysis processes [93,94]. However, solar reactors have some advantages over slow reactors. In slow pyrolysis a part of the feedstock is used to generate the process heat. Therefore it reduces the amount of feedstock available and, at the same time, causes pollution. Hence utilization of solar energy in the pyrolysis process maximizes the amount of feedstock available and overcomes the prolusion problem. Moreover, solar reactors are capable of faster start up and shut down periods compared to slow reactors [95].

\section{Pyrolysis Process Description}

All pyrolysis reactors have definite feedstock size limitations for effective heat transfer and smooth operation. For an example, fluidized bed pyrolysis reactors usually require 2-6 $\mathrm{mm}$ of particle size. Therefore biomass has to be prepared to the desired size by cutting and grinding operations. In addition to sizing, the biomass materials need to be dried to moisture content below $10 \mathrm{wt} \%$ unless a naturally dry material such as straw is available. Drying is essential to avoid adverse effects of water on stability, viscosity, $\mathrm{pH}$, corrosiveness and other liquid properties in the pyrolysis product. By grinding and drying the raw material, the liquid yields will be increased, but at the same time the production costs are increased as well [96]. After drying and grinding, the biomass is fed into the reactor and the pyrolysis process takes place. The char formed in reactor, acts as a vapour cracking catalyst and therefore char removal cyclones are used to separate char from the reactor immediately after pyrolysis. However, some small char particles always pass through the cyclones and are mixed with the liquid 
product. After solid (char) separation, the vapours and the gases need to be quenched rapidly to avoid continuous cracking of the organic molecules. Quenching of the vapours is usually done with pyrolysis liquid condensers, where the vapours are cooled directly with the bio-oil or a hydrocarbon liquid $[16,97,98]$.

\subsection{Feed Preparation}

High water content in biomass has an adverse effect on the pyrolysis process and on the calorific value of pyrolysis bio-oil as well. If the moisture content in biomass feedstock is too high, the bio-oil may be produced with high moisture content which eventually reduces its calorific value. In general, a proper pyrolysis process needs moisture content below $5 \mathrm{wt} \%-15 \mathrm{wt} \%$ [99]. Therefore biomass should undergo a thorough drying process to reduce the water content before pyrolysis is carried out. In contrast, high temperature during the drying process could be a critical issue for the possibility of producing thermal-oxidative reactions, causing a cross-linked condensed system of the components and higher thermal stability of the biomass complex. Dobele et al. conducted an investigation on the effect of the biomass drying process temperature and duration on the properties, chemical composition and yield of pyrolysis product [100]. In their study, wood biomass was dried at temperatures of $200{ }^{\circ} \mathrm{C}$ and $240{ }^{\circ} \mathrm{C}$ with durations of $45 \mathrm{~min}$ and $90 \mathrm{~min}$. The results of their study showed that the increase of drying temperature influenced the yield of pyrolysis products, while the increase in the drying time did not affect it (Figure 5). The quality of the bio-oil is improved with the addition of the drying process for the decrease of the amount of water and acids. The biomass is then ground to 2-6 $\mathrm{mm}$ particle size to yield sufficiently small particles, ensuring rapid reaction in the pyrolysis reactor.

\subsection{Biomass Heating}

Biomass heating or heat transfer in pyrolysis reactors is one of the important concerns. Pyrolysis reactors have two important requirements for heat transfer: (1) to the reactor heat transfer medium (solid and gas in a fluid bed reactor or the reactor wall in an ablative reactor); (2) from the heat transfer medium to pyrolysis biomass. These heat transfers could be gas-solid where heat is transferred from the hot gas to the pyrolysis biomass particles through convection, and solid-solid where conductive heat transfer occurs. About $90 \%$ of heat transfer in fluid bed reactors occurs by conduction, with a small contribution of convection heat transfer of up to $10 \%$ because of utilising good solid mixing. Along with convection and conduction, some radiation heat transfer also occurs in all types of reactor. However, several heating methods are used in different pyrolysis reactors to ensure the efficient conversion of biomass into liquid fuel. Some of the methods are shown in Figure 6 and are listed according to use in reactor types in Table 5. One important aspect in heat transfer is that, as the thermal conductivity of biomass is too low and given the reliance on gas-solid heat transfer, biomass particle size has to be very small to fulfill the requirements of rapid heating to achieve high bio-oil yield. 
Figure 5. Change in the yield of oil, char and gases versus the pyrolysis temperature of wood at drying parameters of: (a) $200{ }^{\circ} \mathrm{C}, 45 \mathrm{~min}$; (b) $200{ }^{\circ} \mathrm{C}, 90 \mathrm{~min}$; (c) $240{ }^{\circ} \mathrm{C}, 45 \mathrm{~min}$; (d) $240{ }^{\circ} \mathrm{C}, 90 \min [100]$.

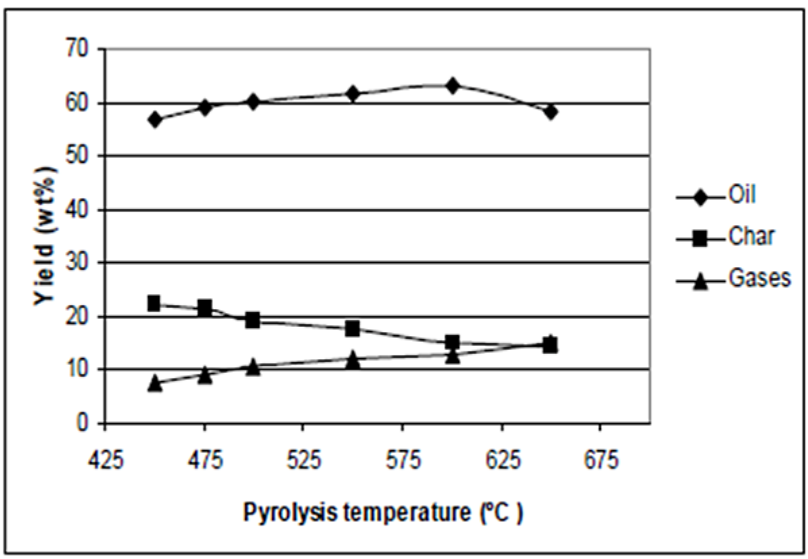

(a)

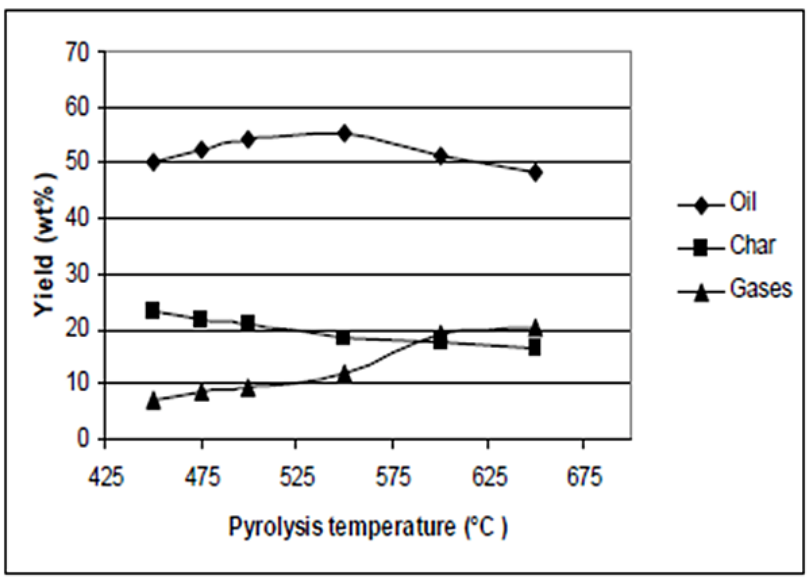

(c)

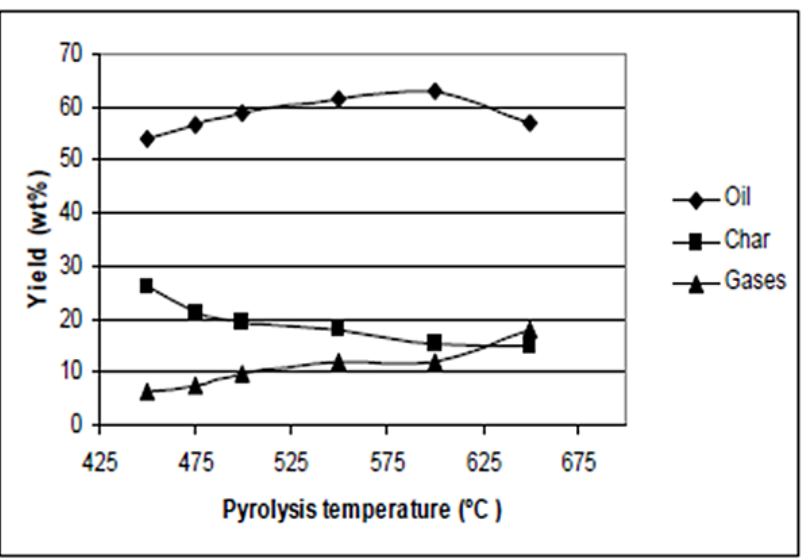

(b)

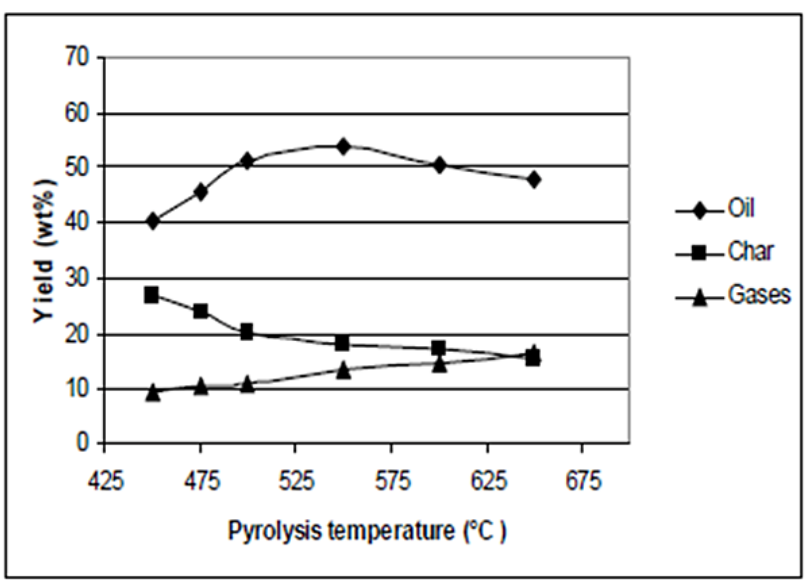

(d)

Figure 6. Methods of heat transfer to a pyrolysis reactor [32].

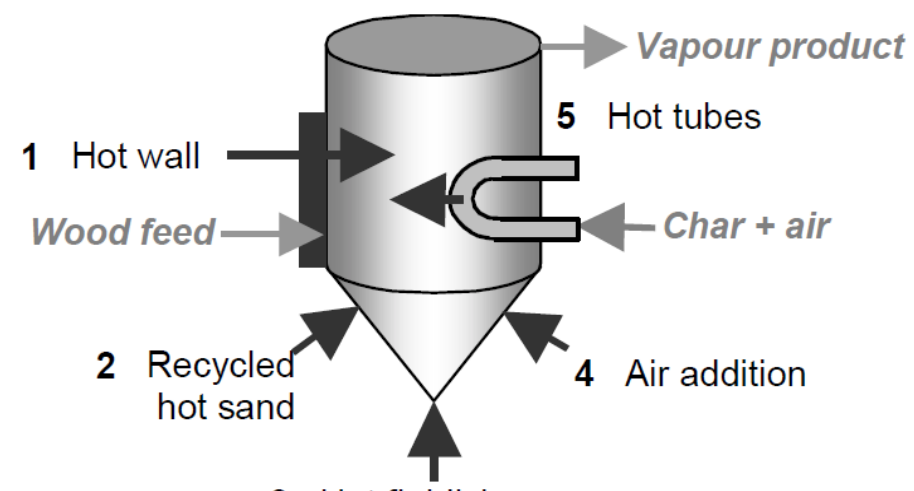

3 Hot fluidising gas 
Table 5. Typical heating methods used in different reactors $[83,87,91]$.

\begin{tabular}{ll}
\hline Heating Method & Reactor Type \\
\hline Heated recycle gas & Bubbling fluidized bed \\
Wall and sand heating & Circulating fluidized bed \\
Gasification of char to heat sand & Rotating cone \\
Direct contract with hot surface & Vacuum \\
Wall heating & Ablative \\
Fire tube & Auger \\
Radio-frequency & Plasma \\
Electromagnetic & Microwave reactor \\
Solar & Fluidized bed/Quartz \\
\hline
\end{tabular}

\subsection{Char Separation}

Char is the intermediate solid residue which is formed in reactors during pyrolysis processes. Quick and effective separation of char is essential because it acts as a vapour cracking catalyst and contributes to the formation of polycyclic aromatic hydrocarbons (PAHs) in pyrolysis processes, particularly at low temperature [101]. Conventionally, chars are separated from reactors using the cyclone method, but this method has the limitation of passing fine particles through the cyclone which then collect in the liquid product where they accelerate aging and create instability problems. Although a number of alternative approaches have been used to overcome this limitation including in-bed vapour filtration [102,103] and rotary particle separation [104], these techniques also have difficulties due to complex interaction between the char and pyrolytic liquid which appears to form a gel-like phase that rapidly blocks the filter. Attempts have been made to solve this problem by using solvents like methanol or ethanol to modify the liquid microstructure [5]. However, it leads to solvent dilution of the liquid product and increases the process cost as well. Therefore research is continuing to find appropriate mechanisms for char separation in pyrolysis processes.

\subsection{Liquids Collection}

True vapour, aerosols and non-condensable gases are mainly available in pyrolysis gaseous products. These require rapid cooling to minimize secondary reactions and to condense the true vapours, while the aerosols require coalescence or agglomeration. However, high temperature heat recovery is not desirable due to the severe fouling in the recuperators [105]. The commonly used methods of this purpose are cooling with a simple heat exchanger, quenching in product oil or in an immiscible hydrocarbon solvent or use of orthodox aerosol capture devices such as demisters and electrostatic precipitators. None of these are very effective except that electrostatic precipitation is likely to be a preferred method for liquid separation at smaller scales up to pilot plant [5].

\section{Pyrolysis Products}

The three primary products obtained from pyrolysis of biomass are char, permanent gases, and vapours that at ambient temperature condense to a dark brown viscous liquid. Maximum liquid production occurs at temperatures between 350 and $500{ }^{\circ} \mathrm{C}[55,106]$. This is because different 
reactions occur at different temperatures in pyrolysis processes. Consequently, at higher temperatures, molecules present in the liquid and residual solid are broken down to produce smaller molecules which enrich the gaseous fraction. Yield of products resulting from biomass pyrolysis can be maximized as follows: (1) charcoal — a low temperature, low heating rate process, (2) liquid products - a low temperature, high heating rate, short gas residence time process, and (3) fuel gas - a high temperature, low heating rate, long gas residence time process. Table 6 summaries the products created at different pyrolysis conditions. Products from pyrolysis processes also strongly depend on the water content in the biomass which produces large quantities of condensate water in the liquid phase [107]. This contributes to the extraction of water-soluble compounds from the gaseous and tar phases, and thus a greater decrease in gaseous and solid products [63].

Table 6. Pyrolysis reactions at different temperatures.

\begin{tabular}{lll}
\hline Condition & Processes & Products \\
\hline Below $350{ }^{\circ} \mathrm{C}$ & $\begin{array}{l}\text { Free radical formation, water } \\
\text { elimination and } \\
\text { depolymerization }\end{array}$ & $\begin{array}{l}\text { Formation of carbonyl and } \\
\text { carboxyl, evolution of CO and } \\
\mathrm{CO}_{2} \text {, and mainly a charred } \\
\text { residue }\end{array}$ \\
\hline $\begin{array}{l}\text { Between } 350{ }^{\circ} \mathrm{C} \\
\text { and } 450{ }^{\circ} \mathrm{C}\end{array}$ & $\begin{array}{l}\text { Breaking of glycosidic linkages } \\
\text { of polysaccharide by } \\
\text { substitution }\end{array}$ & $\begin{array}{l}\text { Mixture of levoglucosan, anhydrides } \\
\text { and oligosaccharides in the form of a } \\
\text { tar fraction }\end{array}$ \\
\hline Above $450{ }^{\circ} \mathrm{C}$ & $\begin{array}{l}\text { Dehydration, rearrangement and } \\
\text { fission of sugar units }\end{array}$ & $\begin{array}{l}\text { Formation of carbonyl compounds } \\
\text { such as acetaldehyde, glyoxal and } \\
\text { acrolein }\end{array}$ \\
\hline Above $500{ }^{\circ} \mathrm{C}$ & A mixture of all above processes & A mixture of all above products \\
\hline Condensation & Unsaturated products condense \\
& and cleave to the char & $\begin{array}{l}\text { A highly reactive char residue } \\
\text { containing trapped free radicals }\end{array}$ \\
\hline
\end{tabular}

\subsection{Pyrolysis Bio-Oil}

Pyrolysis bio-oil is the liquid produced from the condensation of vapour of a pyrolysis reaction. It has potential to be used as a fuel oil substitute. The bio-oils have heating values of $40 \%-50 \%$ of that of hydrocarbon fuels. The main advantages of pyrolysis liquid fuels are [31,38]:

- $\mathrm{CO}_{2}$ balance is clearly positive in biomass fuel;

- Possibility of utilisation in small-scale power generation systems as well as use in large power stations;

- Storability and transportability of liquid fuel;

- High-energy density compared to biomass gasification fuel;

- Potential of using pyrolysis liquid in existing power plants.

Pyrolysis oils; usually referred as bio-oil or bio-crude; are composed of a complex mixture of oxygenated compounds. Bio-oil contains various chemical functional groups such as carbonyls; carboxyls and phenolics that provide both potentials and challenges for utilisation. However; numerous unknown factors are affecting the thermo-physical properties of pyrolysis bio-oil [108,109]. Pyrolysis bio-oils have limitations in fuel quality; phase separation; stability; fouling issues on thermal 
processing and economic viability of pyrolysis bio-oil. Some physical properties and characteristics of bio-oil are described in Table 7.

Table 7. Physical properties and characteristics of pyrolysis bio-oil.

\begin{tabular}{lll}
\hline \multicolumn{1}{c}{ Properties } & \multicolumn{1}{c}{ Oil Characteristics } & \multicolumn{1}{c}{ Reasons } \\
\hline Appearance & Dark red-brown to dark green & $\begin{array}{l}\text { Micro-carbon and chemical } \\
\text { composition in oil }\end{array}$ \\
\hline Odor & Distinctive odor -an acrid smoky smell & $\begin{array}{l}\text { Lower molecular weight } \\
\text { aldehydes and acids }\end{array}$ \\
\hline Density & $\begin{array}{l}\text { Very high compared to fossil fuel } \\
\text { Pyrolysis bio-oil: } 1.2 \mathrm{~kg} / \text { liter } \\
\text { Fossil oil: } 0.85 \mathrm{~kg} / \text { liter }\end{array}$ & $\begin{array}{l}\text { High moisture and heavy } \\
\text { molecule contamination }\end{array}$ \\
\hline Viscosity & $\begin{array}{l}\text { Can vary from as low as } 25 \text { centistokes } \\
\text { (cSt) to as high as 1000 cSt }\end{array}$ & $\begin{array}{l}\text { Wide range of feedstock, water } \\
\text { content and the amount of light } \\
\text { ends collected }\end{array}$ \\
\hline Heating value & Significantly lower than fossil oil & High oxygen content \\
\hline Aging & $\begin{array}{l}\text { Viscosity increase, volatility decrease, } \\
\text { phase separation and deposition of gum } \\
\text { occur with time }\end{array}$ & $\begin{array}{l}\text { Complex structure and high } \\
\text { pH value }\end{array}$ \\
\hline Miscibility & $\begin{array}{l}\text { Miscible with polar solvent but totally } \\
\text { immiscible with petroleum fuel }\end{array}$ & Polar in nature \\
\hline
\end{tabular}

Pyrolysis oil consists of about 300 to 400 compounds [110]. During storage, the pyrolysis oil becomes more viscous due to chemical and physical changes as many reactions continue and volatiles are lost due to aging. Studies found that the reactions and aging effects occur faster at higher temperatures but the effects can be reduced if the pyrolysis oil is stored in a cool place [97,111].

Fahmi et al. concluded that more stable pyrolysis oil can be produced if an energy crop is used [55]. However, this would affect the yield by lowering the organic yield due to the high level of ash/metal content and producing a high level of reaction water, resulting in a reduction of the heating value of the oil as well as risking phase separation. The results of this would imply further investigation is necessary on a trade-off analysis between yield and oil stability. However, feedstock content limits for metals, ash and lignin also need to be identified and addressed in order to produce bio-oil which can be used for commercial applications, which does not change considerably over time, but is still produced at acceptable yield levels and with good heating values.

Shihadeh and Hochgreb found that thermal efficiency of pyrolysis oils is identical to that of diesel fuel in combustion engine operations, but they exhibited excessive ignition delay [112]. Therefore pyrolysis oil requires a moderate degree of preheated combustion air for reliable ignition. However the pyrolysis oil yields, quality and stability can also be modified by process variables such as heating rate, pyrolysis temperature and residence times [113]. This has not been investigated with these feedstocks, and should be the subject for future research. Other factors such as different reactors (ablative and fixed), particle size and char accumulation can affect the yield and quality of the pyrolysis oil by varying its ash content and composition which affects the thermal degradation of these biomass. Until now there is no comprehensive study to minimize these effects. Therefore further research is required, 
in order to obtain an overall picture of thermochemical conversion processes to produce high quality pyrolysis oil.

Commercial pyrolysis bio-oil should maintain its chemical and physical properties such as stability and viscosity. This can be achieved if the oil exhibits high inhomogeneity, processing lower molecular weight compounds. High molecular weight derived compounds present in pyrolysis oil come from the lignin monomers present in the biomass [114]. Therefore biomass with less lignin content is desirable to reduce the heavier molecular weight compounds present in pyrolysis oil and produce a more homogenous liquid [108,115]. Table 8 and 9 shows the comparison of fuel properties and composition between standard diesel oil and pyrolysis bio-oil for different feed stocks. However, some properties listed in the tables such as moisture content and viscosity create issues when using the bio-oil as a fuel. Although the water content (hydrophilic) lowers $\mathrm{NO}_{\mathrm{x}}$, and improves bio-oil's flow characteristics, it also means that bio-oil is immiscible in petroleum fuels (hydrophobic), and lowers the heating value of the fuel. The solids entrained in the bio-oil principally contain fine char particles that are not removed by the cyclones. The viscosity of bio-oil may become problematic as the bio-oil is stored over time, as unfavourable reactions take place that make the liquid too viscous to be a viable fuel. To address some of the obstacles of using bio-oil as a fuel, efforts to modify and improve the quality of bio-oil have been made [116].

Initially the interest of using bio-oil was driven by concerns for potential shortages of crude oil, but in recent years the ecological advantages of biomass fuels have become an even more important factor. Pyrolysis bio-oil presents a much better opportunity for high efficiency energy production compared to traditional biomass fuel such as black liquor or hog oil. Therefore a significant effort has been spent on research and development directed to the application of bio-oil for the generation of heat and power and for use as a transport fuel. Unfortunately bio-oils have not reached commercial standards yet due to significant problems during its use as fuel in standard equipment such as boilers, engines and gas turbines constructed for operation with petroleum-derived fuels. The main reasons for this are poor volatility, high viscosity, coking, and corrosiveness of bio-oil. In this section, application of bio-oil in boilers, turbines and diesel engines is summarised. However, pyrolysis bio-oils have a good potential to replace conventional diesel fuel.

Bio-oil can be used as a substitute for fossil fuels to generate heat, power and chemicals. Short-term applications are boilers and furnaces (including power stations), whereas turbines and diesel engines may become users in the somewhat longer term (Figure 7). Upgrading of bio-oil to a transportation fuel quality is technically feasible, but needs further development. Transportation fuels such as methanol and Fischer-Tropsch fuels can be derived from bio-oil through synthesis gas processes. Furthermore, there is a wide range of chemicals that can be extracted or derived from bio-oil. A general overview is depicted below. 
Table 8. Properties No.2 Diesel fuel and pyrolysis bio-oil from different feed stocks $[31,54,65,82]$.

\begin{tabular}{lccccc}
\hline & $\begin{array}{c}\text { Moisture } \\
\text { Content } \mathbf{( w t \% )}\end{array}$ & $\mathbf{p H}$ & $\begin{array}{c}\text { Viscosity } \\
\mathbf{m m}^{\mathbf{2} / \mathbf{s}}\end{array}$ & $\begin{array}{c}\text { HHV } \\
\mathbf{( M J / k g )}\end{array}$ & $\begin{array}{c}\text { LHV } \\
\mathbf{( M J} / \mathbf{k g})\end{array}$ \\
\hline Diesel & - & 1 & 2.39 & 44.7 & 42.5 \\
Wood & $15-30$ & 2.5 & $40-100$ & 16 & 19 \\
Willow & 17.4 & 2.68 & 53.2 & 18.4 & 16.8 \\
Straw & 47.4 & 3.45 & 17.2 & 13.6 & 11.6 \\
Sweet grass & 24.7 & 2.87 & 34.2 & 16.4 & 14.8 \\
Dactylis glomerata & 43.05 & 3.12 & 9.2 & 17.6 & 15.7 \\
Festuca arundiance & 34.1 & 3.18 & 10.9 & 16.7 & 14.5 \\
Lonium perenne & 48 & 3.16 & 6.5 & 15.8 & 13.7 \\
Reed canary grass & 23.2 & 3.01 & 31.6 & 17.1 & 15.3 \\
Rice husk & 27.2 & 2.8 & 128 & - & 16.4 \\
Corn stalk & 26.9 & 2.3 & 140 & - & 16.8 \\
Cotton talk & 26.7 & 2.6 & 156 & - & 17.2 \\
Sawdust & 24 & 2.1 & 140 & - & 17.4 \\
Palm shells & 10 & 2.7 & 14.6 & - & 20.6 \\
\hline
\end{tabular}

Table 9. Elementary analysis of No 2 Diesel, coal and pyrolysis bio-oil from different feed stocks $[31,54,65,82]$.

\begin{tabular}{lccccc}
\hline & $\mathbf{C}(\mathbf{w t} \%)$ & $\mathbf{H}(\mathbf{w t} \%)$ & $\mathbf{N}(\mathbf{w t} \%)$ & $\mathbf{S} \mathbf{( w t \% )}$ & $\mathbf{O}(\mathbf{w t} \%)$ \\
\hline Diesel & 86 & 11.1 & 1 & 0.80 & 0 \\
Wood & $55-58$ & $5.5-7$ & $0-0.2$ & 0 & $35-40$ \\
Willow & 43.17 & 7.15 & 0.10 & 0.10 & 49.49 \\
Straw & 28.2 & 8.78 & 0.10 & 0.10 & 62.83 \\
Sweet grass & 38.3 & 7.42 & 0.10 & 0.10 & 54.08 \\
Dactylis glomerata & 36.75 & 8.82 & 1.88 & 0.10 & 52.46 \\
Festuca arundiance & 32.05 & 9.76 & 1.41 & 0.10 & 56.69 \\
Lonium perenne & 30.64 & 9.63 & 0.77 & 0.10 & 58.86 \\
Reed canary grass & 38.42 & 7.89 & 0.10 & 0.10 & 53.49 \\
Sesame stalk & 61.69 & 7.96 & 29.37 & 0.98 & - \\
Rapeseed & 74.04 & 10.29 & 11.70 & 3.97 & - \\
Miscanthus & 48.1 & 5.4 & 42.2 & 0.5 & .01 \\
Cherry stone & 46.9 & 7.9 & 45.1 & 0.1 & - \\
Sunflower oil cake & 66.5 & 9.2 & 4.5 & 19.8 & - \\
Sugar cane bagasse & 46.27 & 6.55 & 46.9 & - & $0.1-0.15$ \\
Jute stick & 47.18 & 8.36 & 44.1 & - & - \\
Rice straw & 41.4 & 5 & 39.9 & 0.7 & 0.1 \\
Palm shells & 53.5 & 6.7 & 0.44 & 0.02 & 39.37 \\
\hline
\end{tabular}


Figure 7. Various applications of pyrolysis bio-oil.

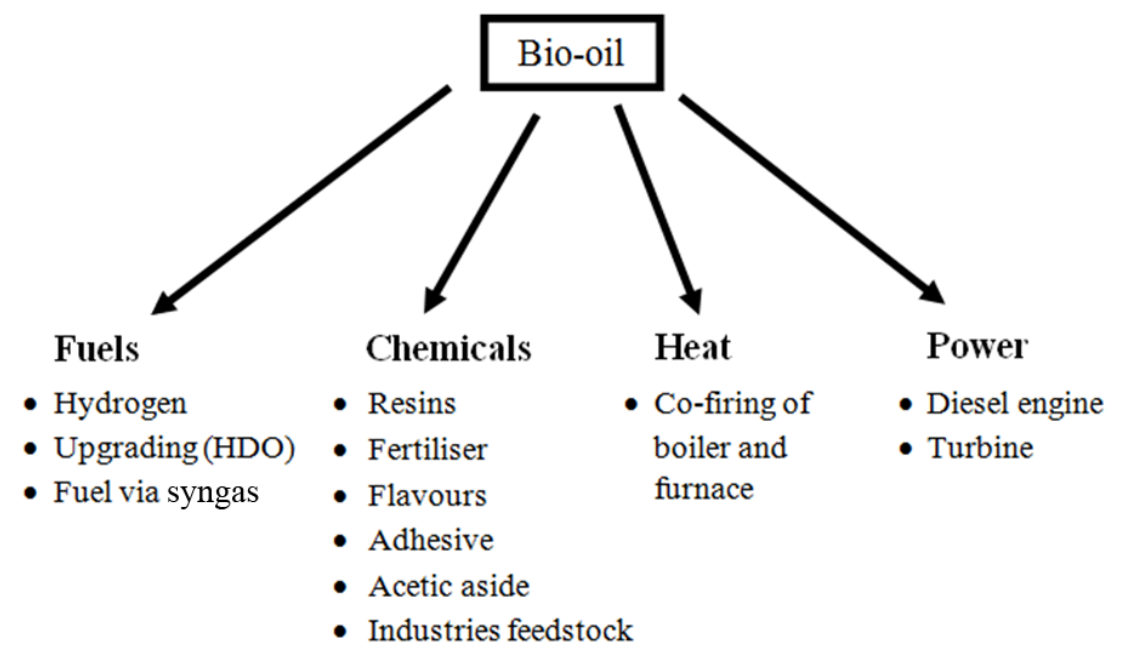

\subsubsection{Furnaces and Boilers}

Furnaces and boilers are commonly used for heat and power generation. Technologically they produce less efficient combustion compared to turbines and engines. On the other hand, furnaces and boilers can operate with a great variety of fuels ranging from natural gas and petroleum distillates to sawdust and coal/water slurries. Therefore bio-oil seems to be more suitable for boiler applications as long as it meets acceptable emission levels, economic viability and consistent quality characteristics. Several studies [117-119] have been conducted using pyrolysis bio-oil in boiler applications to replace heavy fuel oil. The important findings of these studies could be summarized as follows:

- Pyrolysis bio-oils have significantly different combustion characteristics compared to fossil fuels;

- Bio-oils with high viscosity and high solids and water content exhibit worse combustion performances in boilers;

- Different pyrolysis bio-oils differ in combustion behaviour and exhaust gas emissions;

- The flame from bio-oil combustion is longer compared to that of standard fossil oil;

- Harmful gas emissions from pyrolysis bio-oil in boiler applications are lower than from burning heavy fuel oils except for particulate levels;

- Some modifications of the burners and boilers are required for proper utilization of pyrolysis bio-oil in heat and power generation.

\subsubsection{Diesel Engines}

Diesel engines offer high efficiency with oil combustion and can be adapted to the combined cycle power generation. Bio-oil can be utilized in medium and slow speed conventional diesel engines. However some critical problems can occur while using bio-oil in diesel engines. These include carbon deposition on pistons and other components of the engine combustion chamber; filter plugging; injector coking; heavy gum and wax formation and deposition; cold weather starting difficulty; excessive engine wear; poor atomisation; piston ring sticking and fuel pump failure of engine 
lubricating oil due to polymerisation [120-122]. The reasons for these problems were reviewed and reported by Jayed et al. [123].

Researchers around the world have been continuing to utilise pyrolysis bio-oil in conventional diesel engine applications over the last few decades. Solantausta et al. efficiently used pyrolysis bio-oil in a medium speed diesel engine [124]. They found some difficulties in adjusting the injection system for excessive variability in the composition of bio-oil. They also reported wear and corrosion in injection and pump materials and high $\mathrm{CO}$ emissions due to high moisture, acids and particles in pyrolysis bio-oil. Some other similar studies suggested that the application of pure pyrolysis oils should be limited to low speed diesel engines with relatively high compression ratios, but blends of pyrolysis oil and methanol could be used in high speed engines, especially with cetane improving additives such as nitrated alcohol [125-127]. However straight pyrolysis bio-oils have not yet been proven for diesel engine applications because of several difficulties, but it seems possible to overcome these problems with improvements to the pyrolysis process and use of better materials for engine components.

\subsubsection{Gas Turbines}

Gas turbines can be used for many applications including driving power generators, industrial production processes and providing power for aircraft. Gas turbines are currently operated using liquid and gaseous petroleum fuels. If properly modified and redesigned to accommodate some unusual properties of bio-fuel, gas turbines can efficiently burn biomass pyrolysis oil. Strenziok et al. smoothly operated a small commercial gas turbine with a rated electrical power output of $75 \mathrm{~kW}$ with biomass pyrolysis bio-oil [128]. In their study, modifications had to be made to the turbine to allow it to operate in a dual fuel mode with two separate fuel systems: one for standard diesel and another for biomass pyrolyzed oil. Along with a moderate reduction of turbine power not related only to fuel type, excessive carbon deposition in the combustion chamber, slag buildup in the exhaust system and significantly higher $\mathrm{CO}$ and $\mathrm{HC}$ emissions were observed when using bio-oil compared to diesel fuel.

\subsubsection{Chemicals}

Pyrolysis oils have the potential to produce high-value chemicals for browning/flavouring of food, phenols (adhesives for wood), fertilizer, acetic acid, sugars and also chemicals for other industrial applications [129]. However studies on extracting useful chemicals from pyrolysis oil are ongoing and need further development.

\subsection{Bio-Char From Pyrolysis}

Thermal degradation of lignin and hemicellulose results in considerable mass loss in the form of volatiles, leaving behind a rigid amorphous carbon matrix which is referred as bio-char. Depending on the biomass and pyrolysis conditions, 10 to $35 \%$ bio-char is produced. Rocha et al. carried out an investigation to demonstrate bio-char yield variation for different temperature regions in a fluidised bed pyrolysis reactor [130]. In their investigation, three different temperature regions were found to produce different bio-char yields during pyrolysis (Figure 8 ). At a low temperature $\left(450-500{ }^{\circ} \mathrm{C}\right)$ zone, 
bio-char quantity was high due to low devolatilisation rates and low carbon conversion. In a second moderate temperature $\left(550-650^{\circ} \mathrm{C}\right)$ zone, the production of bio-char was reduced dramatically. The maximum yield in this region was found to be about 8 to $10 \%$ of bio-char. In the high temperature (over $650^{\circ} \mathrm{C}$ ) zone, bio-char yield was very low.

Figure 8. Charcoal (or bio-char) yields variation versus average temperature in the fluidised bed [130].

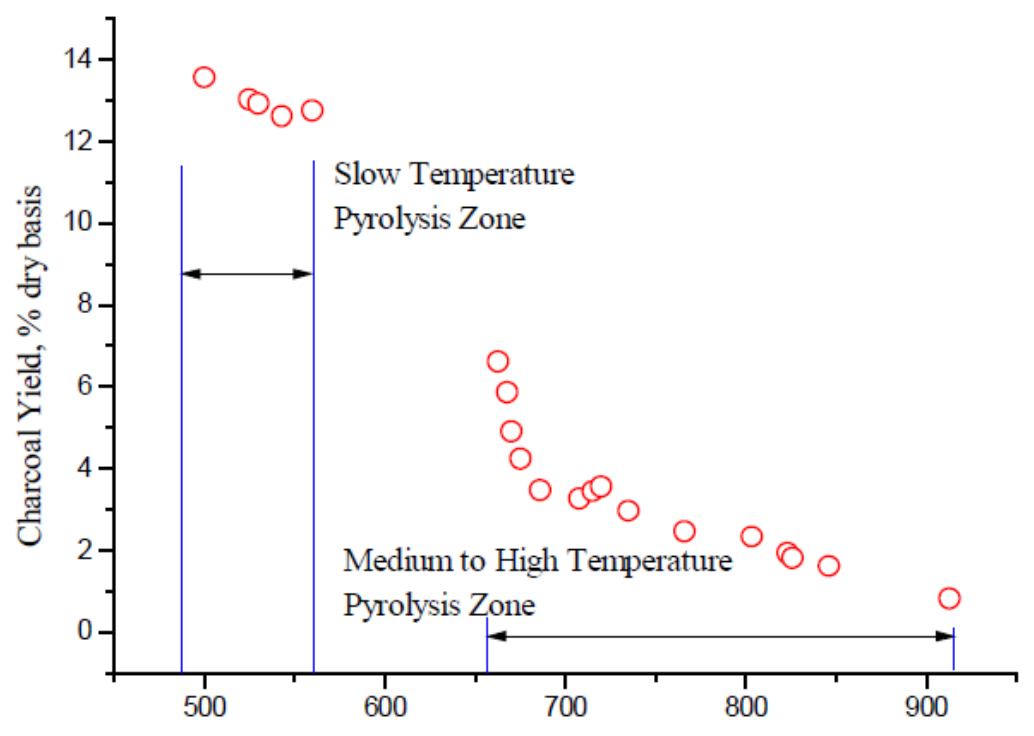

Average Bed Temperature of the Reactor, ${ }^{\circ} \mathrm{C}$

Bio-char physical characteristics are greatly affected by the pyrolysis conditions such as reactor type and shape, biomass type and drying treatment, feedstock particle size, chemical activation, heating rate, residence time, pressure, flow rate of inert gas, etc. [131-136]. For example, pyrolysis operating conditions like higher heating rate (up to $105-500{ }^{\circ} \mathrm{C} / \mathrm{s}$ ), shorter residence time and finer feedstock produce finer bio-char whereas slow pyrolysis with larger feedstock particle size results in a coarser bio-char. Moreover wood-based biomass generally produces coarser bio-char. On the other hand, crop residues and manures generate a finer and more brittle structured bio-char in pyrolysis processes [137].

Bio-char mainly consists of carbon along with hydrogen and various inorganic species in two structures: stacked crystalline graphene sheets and randomly ordered amorphous aromatic structures [138]. In the aromatic rings, H, O, N, P and S are commonly incorporated as heteroatoms which have a great influence on bio-char physical and chemical properties [139]. However composition, distribution and proportion of these molecules in bio-char depend on a variety of factors including source materials and the pyrolysis methodology used [92,140-142]. Nevertheless, depending upon composition and physical properties, bio-char can be utilised in various industrial processes such as: solid fuel in boilers, producing activated carbon, making carbon nanotubes, producing hydrogen rich gas, etc. [44]. 


\subsection{Syngas}

Similar to char, about $10 \%$ to $35 \%$ of bio-gas is produced in slow pyrolysis processes. However, a higher syngas yield is possible in flash pyrolysis with high temperatures [143]. For example, He et al. investigated syngas production from pyrolysis of MSW in a bench-scale downstream fixed-bed reactor over a temperature range of $750{ }^{\circ} \mathrm{C}-900{ }^{\circ} \mathrm{C}$ using calcined dolomite as a catalyst [143]. Their study achieved $78.87 \%$ gas yield at $900{ }^{\circ} \mathrm{C}$. Likewise, Tang and Huang produced up to $76.64 \%$ syngas in a radio frequency plasma pyrolysis reactor [83]. However, syngas yield is strongly influenced by the pyrolysis temperature.

Reactor temperature has a significant influence on pyrolysis processes and resulting product distribution. As the pyrolysis temperature increases, the moisture inside the biomass evaporates first, and then thermal degradation and devolatilisation of the dried portion of the particles take place. At the same time, tar is produced and volatile species are gradually released from the particles' surface. The volatile species and tar then undergo a series of secondary reactions such as decarboxylation, decarbonylation, dehydrogenetaion, deoxygenation and cracking to form components of syngas [144]. Therefore higher temperatures favour tar decomposition and the thermal cracking of tar to increase the proportion of syngas, resulting in decreased oil and char yields [47,143,145]. Studies have also shown that an increase in reactor temperature increased the syngas flow rate which lasts for a shorter period of time and then reduces dramatically $[36,146]$.

Moisture content influences the heat transfer process in pyrolysis, having an unfavourable effect on syngas production. High moisture content contributes to the extraction of water-soluble components from the gaseous phase, hence causing a significant decrease in gaseous products [147]. For a given temperature, dry biomass produces the greatest quantity of gas at the early stage of pyrolysis, whereas with wet biomass the production of the greatest quantity occurs later in the run. This occurs because an increase in humidity leads to an increase in drying time [63].

Syngas mainly consists of hydrogen $\left(\mathrm{H}_{2}\right)$ and carbon monoxide $(\mathrm{CO})$. It also contain small amount of carbon dioxide $\left(\mathrm{CO}_{2}\right)$, water, nitrogen $\left(\mathrm{N}_{2}\right)$, hydrocarbons such as $\mathrm{CH}_{4}, \mathrm{C}_{2} \mathrm{H}_{4}, \mathrm{C}_{2} \mathrm{H}_{6}$, tar, ash, etc. depending on biomass feedstock and pyrolysis conditions [44,61,85,145]. These components are obtained during several endothermic reactions at high pyrolysis temperatures. $\mathrm{H}_{2}$ is produced from the cracking of hydrocarbons at higher temperatures. $\mathrm{CO}$ and $\mathrm{CO}_{2}$ are the indicators of the presence of oxygen in the biomass. Those components mainly originate from the cracking of partially oxygenated organic compounds. Therefore, as a highly oxygenated polymer, the amount of cellulose present in the biomass is an important factor determining the amount of carbon oxides produced [148,149]. The light hydrocarbons such as $\mathrm{CH}_{4}, \mathrm{C}_{2} \mathrm{H}_{4}, \mathrm{C}_{2} \mathrm{H}_{6}$, etc. may be due to the reforming and cracking of heavier hydrocarbons and tar in the vapour phase [144]. However, the composition of syngas is clearly affected by the reactor temperature as shown in Figure $9 . \mathrm{H}_{2}$ increases sharply and $\mathrm{CO}$ increases slowly with the increase of the temperature while other components show an opposite tendency. The molar ratio of $\mathrm{H}_{2}$ and $\mathrm{CO}$ in syngas is an important factor that determines its possible applications. For example, a higher $\mathrm{H}_{2} / \mathrm{CO}$ molar ratio is desirable to produce Fisher-Tropsch synthesis for the production of transportation fuel and to produce hydrogen for ammonia synthesis [85], so optimisation of reaction temperature in pyrolysis is a critical issue for syngas production. 
Figure 9. Gas composition of pyrolysis of cotton stalks versus pyrolysis temperature [143].

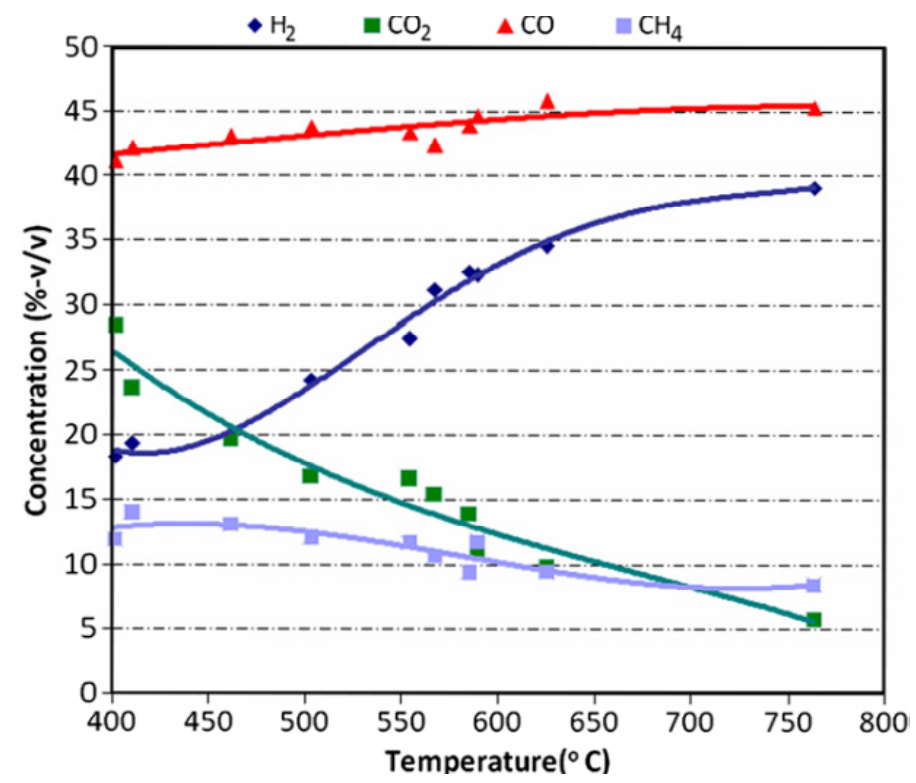

Syngas from biomass pyrolysis could be a renewable alternative fuel for internal combustion (IC) engines and industrial combustion processes. Commercial petrol and diesel engines can be easily converted to use gaseous fuel for the use of power generation, transportation and other applications [60,150,151]. However many commercial gaseous fuel IC engines were used between 1901 and 1920. After then the trend declined due to available cheap liquid fuels. Recently interest has again developed in the use of syngas in IC engines due to the emergence of the need for renewable fuel engines [152].

Shah et al. found similar thermal efficiencies for syngas and petrol used as fuel in naturally-aspirated, four-stroke, and single-cylinder IC engines [153]. Mustafi et al. operated a single cylinder spark ignition engine using syngas as fuel [154]. Their study found that syngas produced about 30\% less engine power output compared to petrol. Given the concern of exhaust emissions, syngas produced a significantly lower amount of unburnt hydrocarbon (HC) and carbon monoxide (CO), but nitrogen oxides $\left(\mathrm{NO}_{\mathrm{x}}\right)$ emission was quite high. This is because $\mathrm{CO}$ and $\mathrm{H}_{2}$ in syngas have relatively high flame speed and flame temperature which generate higher temperatures in engine cylinders and hence accelerate production of $\mathrm{CO}_{2}$ and $\mathrm{NO}_{\mathrm{x}}$. Similar results have been reported in many other studies [155-157] which operated IC engines with syngas. However, the generation of $\mathrm{NO}_{\mathrm{x}}$ emissions from syngas can be reduced by reducing the heating value, inserting inert gas and increasing the $\mathrm{CO} / \mathrm{H}_{2}$ ratio [158].

\section{Catalysts in Pyrolysis}

A catalyst increases the rate of a chemical reaction without consuming or changing itself during the reaction. Its plays an important role and is widely applied in biomass pyrolysis processes. In general; catalysts are used to enhance pyrolysis reaction kinetics by cracking higher molecular weight compounds into lighter hydrocarbon products [159]. However; different catalysts have different product distributions in different operating conditions. Depending of application; pyrolysis catalysts can be classified into three different groups. The first group is added to the biomass before being fed 
into the reactor [9]. The second group is added into the reactor; therefore permitting immediate contact with vapours; solid and tar [160]. The third group is placed in a secondary reactor located downstream from the pyrolysis reactor [161]. However, Han and Kim divided catalysts into four groups depending on composition [162]. These included: dolomite catalyst, Ni-based catalysts, alkali metal catalysts and novel metal catalysts. Calcined dolomite as a catalyst is attracting much attention because it is inexpensive, abundant and significantly reduces tar formation in the product gas [163]. Therefore calcinate dolomite was extensively investigated in different reactors such as fixed bed [144,164,165] and fluidised bed reactors [166-168]. He et al. used calcined dolomite as a catalyst in a lab-scale continuous feeding fixed-bed reactor for pyrolysis of municipal solid waste [144]. This study found that the presence of calcined dolomite influenced greatly the product yields by increasing significantly the amount of syngas production while decreasing oil and char yield. However calcined dolomite catalyst has some limitations including low melting point which makes it unstable at high temperatures, not effective in heavy tar cracking and difficult to achieve or exceed $90 \%-95 \%$ tar conversion. However numerous others types of catalysts have been studied in biomass pyrolysis to enhance productivity [169]. Some of these included $\mathrm{Ni}, \mathrm{CeO}_{2}, \mathrm{Al}_{2} \mathrm{O}_{3}$ [170], alumina [171], sodium feldspar [9], $\mathrm{CeO}_{2}, \mathrm{Rh}, \mathrm{SiO}_{2}$ [172], Li, $\mathrm{Na}, \mathrm{K}$ carbonates [173], $\mathrm{Na}_{2} \mathrm{CO}_{3}, \mathrm{~K}_{2} \mathrm{CO}_{3}, \mathrm{ZnCl}_{2}$ [174], $\mathrm{Ni} / \mathrm{SiO}_{2}-\mathrm{N}$ [175], zeolite [176] and $\mathrm{ZrO}_{2}$ [177]. These $\mathrm{Ni}$ and alkali metal based catalysts were proven to be effective in heavy tar elimination and achieving more than $99 \%$ tar destruction, but were found to become inactive by carbon deposition [162]. Moreover, most of those were used only at small scale to improve gas production for research purposes. Addition of this catalyst resulted in the lowering of char yield and did not substantially impact on oil yield. Therefore, development of commercial scale, efficient and stable catalysts for pyrolysis is a future challenge.

\section{Energy Consumption in Pyrolysis}

Large amounts of thermal energy are needed to maintain suitable pyrolysis temperatures in the reactor wall or heat carrier. Energy is also needed for grinding and drying the feed material into a usable particle size. Numerous electric motors are required to provide the work to achieve the different flow rates, pressures and power the filtration systems. Therefore, energy efficiency is an important measure for identifying the performance of a pyrolysis process which can be expressed as follows:

$$
\eta_{\text {energy }}=\frac{E_{\text {Biofuel }}}{E_{\text {Feedstock }}+E_{\text {Pyrolysis }}}
$$

where $\eta_{\text {Energy }}$ is the process energy efficiency; $E_{\text {Biffuel }}$ is the energy content in the product bio-fuel; $E_{\text {Feedstock }}$ is the energy content in the biomass feedstock and $E_{\text {Pyrolysis }}$ is the external energy consumption in the pyrolysis process. In general, the three components can be considered in the calculation of energy consumption for pyrolysis as follows:

$$
E_{\text {Pyrolysis }}=E_{\text {Drying }}+E_{\text {Target }}+E_{\text {Reaction }}
$$

The first component ( $E_{\text {Drying }}$ ) of energy involves dewatering the wet biomass to dry biomass. The second component ( $E_{T \text { arget }}$ ) of energy is used to heat dried biomass to the pyrolysis temperature, and the third component ( $E_{\text {Reaction }}$ ) of energy is consumed to decompose the biomass during the pyrolysis 
reaction. The required energy can be supplied by pyrolysis by-products. Bramer and Holthuis conducted a study to find energy required to run a small scale $(30 \mathrm{~kg} / \mathrm{h}$ biomass $)$ pyrolysis system using a PyRos reactor [82]. This study concluded that about $5.48 \%$ of produced energy is sufficient for the energy need for running the pyrolysis process. This energy can be obtained by combusting one of the two by-products - the bio-char, or all the produced gas with a small proportion of the bio-char. Moreover, fraction of energy recovery from biomass can also be good measure to determining the effectiveness of biomass pyrolysis which is the ratio of energy available in the products and energy containing in biomass. Stals et al., have conducted such an analysis and achieved 35-39 percent energy recovery in flash pyrolysis of different hardwoods [178]. However the results presented in these studies are not enough to make a final conclusion regarding the energy efficiency of industrial scale pyrolysis plants. In order to obtain a clear energy picture and hence improve the energy efficiency, a comprehensive energy audit should be conducted in an industrial scale pyrolysis plant.

\section{Pyrolysis Economics}

Economic viability is the key factor in the development of commercial pyrolysis processes. Currently, pyrolysis products are unable to compete economically with fossil fuels due to high production costs. The pyrolysis technology has to overcome a number of technical and non-technical barriers before industry can implement their commercialisation and usage [179]. Production cost of pyrolysis product is higher compared to production of fossil fuel. The main component of pyrolysis plants are the reactor, although it represents only $10 \%-15 \%$ of the total capital cost. The rest of the cost consists of biomass collection, storage and handling, biomass cutting, dying and grinding, product collection and storage, etc.

The cost of a pyrolysis production plant could be classified into two main categories: capital investment, and operating or variable costs. Capital or fixed cost includes: pyrolysis module, basic equipment, feed handling and storage, and development of facilities (land, road, transport, building etc.). The fixed cost primarily depends on the technology, plant size and biomass feedstock. Variable costs include biomass harvesting or feedstock, maintenance, product transport, labour, utility, transport etc. The percentage of approximate contributions of different component on variable cost is given in Table 10.

Table 10. Variable cost for a pyrolysis plant [116].

\begin{tabular}{lc}
\hline \multicolumn{1}{c}{ Items } & Percentages \\
\hline Biomass harvesting or feedstock & $23 \%-30 \%$ \\
Maintenance & $17 \%-24 \%$ \\
Utilites & $22 \%-25 \%$ \\
Labor & $12 \%-19 \%$ \\
Grinding & $7 \%-9 \%$ \\
Transportation & $5 \%-7 \%$ \\
\hline
\end{tabular}

Several factors are also associated with the cost of biomass pyrolysis energy conversion which includes process technology, the scale of operation, feedstock, year of construction, and so on. Moreover, scale-up is an increasingly important issue as pilot and demonstration plants have to be 
commercially realized. The annual production costs can be calculated using the annuity method which is given by $[180,181]$. Annual cost $(\$)=$ Operating cost + (annualized capital cost — annualized salvage value). The annualized capital costs can be determined by Equation (4) [180,181]:

$$
A C C=\frac{(\text { total plant } \cos t+\text { construction } \cos t)}{\left\{1-(1+i)^{-N_{p}}\right\}} \times i_{p}
$$

where, ACC is the annualised capital cost per year; $i_{\mathrm{p}}$ is the interest rate and $N_{\mathrm{p}}$ is the plant life time. The construction cost can be given by:

$$
\text { Construction } \cos t=\sum_{j=1}^{N_{c}} \frac{\text { Total plant } \cos t}{N_{c}} j i_{c}\left(1+i_{p}\right)^{N_{c}-j+1}
$$

where $N_{\mathrm{c}}$ is the construction period, $i_{\mathrm{c}}$ is the construction financing/interest rate and $i_{\mathrm{p}}$ is the project financing rate.

Table 11. Parameters used in production cost calculation [180].

\begin{tabular}{ll}
\hline Plant capacity & $0.3,100$ and $1000 \mathrm{~kg} / \mathrm{h}$ rice husk \\
Plant life & 10 years \\
Annual operating time & $3120 \mathrm{~h} @ 10 \mathrm{~h} /$ day \\
Maintenance labour & $1 \%$ of FCI \\
Maintenance materials & $3 \%$ of FCI \\
Overheads & $2 \%$ of FCI \\
Insurance & $2 \%$ of FCI \\
Other fixed operating costs & $1 \%$ of FCI \\
Interest rate & $10 \%$ \\
Feedstock cost & 20 US $\$ /$ ton \\
Labour hire rate & 1 US $\$ / \mathrm{h}$ \\
Number of labours & 1,5 and 20 respectively for the three different plant \\
& capacity mentioned above \\
Nitrogen gas price & $5 \mathrm{US} \$$ per cylinder of $6.3 \mathrm{~m}^{3}$ \\
Electricity price & $0.04 \mathrm{US} \$ / \mathrm{kWh}$ \\
Catalyst cost & $100 \mathrm{US} \$ / \mathrm{kg}$ \\
Catalytic life & 1 year \\
\hline
\end{tabular}

The plant cost is the summation of the cost of the major pieces of base equipment. This can be determined through published data and quotes from the manufacturers. The base equipment cost is multiplied by different factors such as a direct-cost factor, a building factor, site improvement factor and utilities factor to obtain total plant cost. The summation of total plant costs and construction costs is known as fixed capital cost or fixed capital investment (FCI). Most of the operating costs (maintenance labour, maintenance materials, overheads and insurance, etc.) can be considered as the percentages of fixed capital investment (FCI).

Islam and Ani determined unit production costs of rice husk pyrolysis for three different sizes of plant capacity $(0.3 \mathrm{~kg} / \mathrm{h} \quad(0.0072$ tonne/day $), 100 \mathrm{~kg} / \mathrm{h} \quad(2.4$ tonne/day $)$ and $1000 \mathrm{~kg} / \mathrm{h}$ (24 tonne/day) for fixed fluidized bed fast pyrolysis (FBFP) and fluidized bed fast pyrolysis with catalytic treatment (FBFPCT) [180]. Table 11 shows the assumptions and costs of the various 
parameters they used to determine production costs for three different scales pyrolysis units. The feedstock, rice husk, was dried prior to pyrolysis to reduce the water content of the pyrolysis oil. The unit production cost of primary pyrolysis oil and catalytically treated oil for three different plant capacity investigated by Islam and Ani [180] is shown in Figure 10.

Figure 10. Bio-oil production cost of rice husk pyrolysis as a function of plant capacity [180].

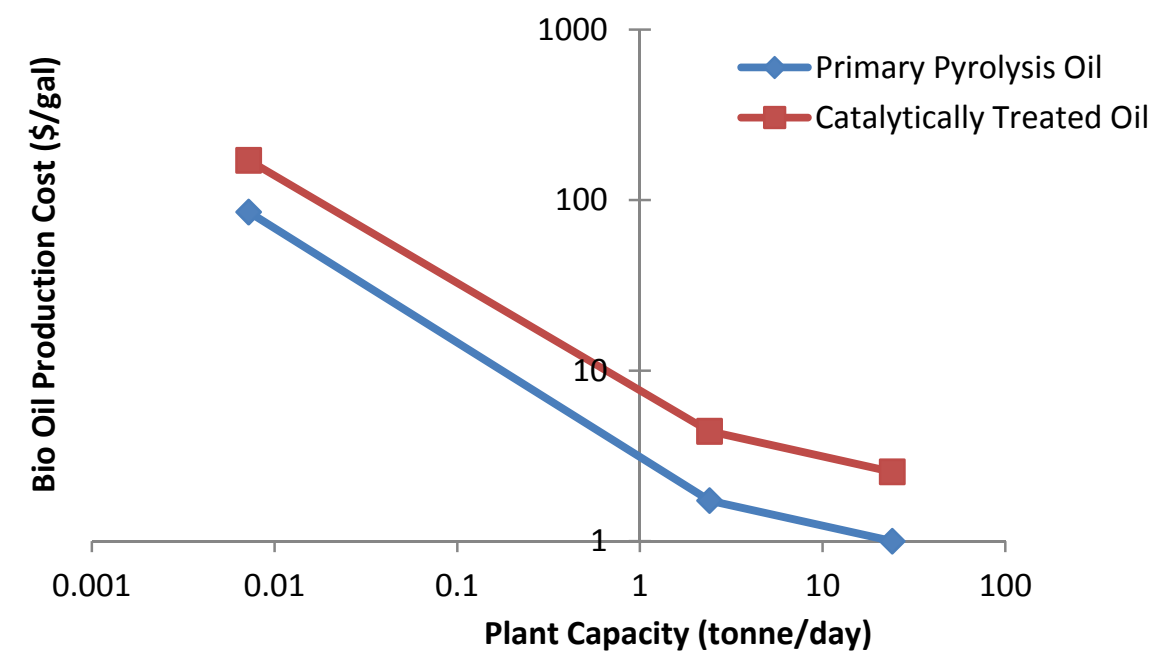

It can be seen from Figure 10 that the greater the plant size, lower is the unit production cost, as expected. It can also be observed that small plant dramatically increase the production cost. Based on the data of Figure 10, the unit cost of production of primary pyrolysis oil from $0.3 \mathrm{~kg} / \mathrm{h}$ ( 0.0072 tonne/day) plant is about 50 times higher than the unit cost of production from $100 \mathrm{~kg} / \mathrm{h}$ (2.4 tonne/day) and about 100 times higher than the unit cost of production from $1000 \mathrm{~kg} / \mathrm{h}$ (24 tonne/day).

Several other studies have been conducted for economic assessments of bio-energy production from biomass through pyrolysis during the last two decades. Findings of these studies including findings of Islam and Ani [180] for plant capacity of more than 1 tonne/day are summarised and presented in Table 12.

Though it is believed that the unit cost of production generally decreases with increase in plant size, it cannot be correlated using the data from Table 12 as there were various types of feedstocks which had different physical and chemical properties, and various types of pyrolysis process used. Some other parameters, such as revenue, product outputs, plant life, etc., have also impact on unit production cost. However, it is possible to develop a relationship between production costs and plant sizes if we have data on plant sizes for a single type of feedstock. Using the data available in Table 12 for only wet wood pyrolysis (though there could be slight variation in assumptions and parameters), the relationship between production costs and plant sizes can be developed and are shown in Figure 11. It can be clearly seen from Figure 11 that the production cost decreases exponentially with increase in plant size. It is also to be noted that for plant size of 1000 tonnes/day or more, the production cost of bio-oil from wet wood pyrolysis is about $\$ 0.6 /$ gallon. 
Table 12. List of the plant size, feedstock type and price, estimated bio-oil cost, and capital investment as reported in the various reports $[65,96,116,180-186]$.

\begin{tabular}{cccccccc}
\hline $\begin{array}{c}\text { Plant Size } \\
\text { (tonne/day) }\end{array}$ & Feedstock & $\begin{array}{c}\text { Capital } \\
\text { Investment } \\
\text { (million \$) }\end{array}$ & $\begin{array}{c}\text { Annual } \\
\text { Operating } \\
\text { Costs } \\
\mathbf{( M ~ \$ ) ~}\end{array}$ & $\begin{array}{c}\text { Feed } \\
\text { Costs } \\
\text { (\$/tonne) }\end{array}$ & $\begin{array}{c}\text { Production } \\
\text { Costs } \\
\mathbf{( \$ / g a l )}\end{array}$ & References & $\begin{array}{c}\text { Type of } \\
\text { pyrolysis } \\
\text { process }\end{array}$ \\
\hline 2000 & Corn Stover & 200 & 12.3 & 83 & 0.26 & {$[182]$} & Fast pyrolysis \\
1650 & Wood pellet & 180 & 12 & - & 0.24 & {$[181]$} & Fast pyrolysis \\
1000 & Dry wood & 68 & 10.6 & 44 & 0.41 & {$[184]$} & Fast pyrolysis \\
1000 & Wet wood & 72 & 11.3 & 30 & 0.60 & {$[185]$} & Flash pyrolysis \\
1000 & Peat & 76 & 10.2 & 20 & 0.61 & {$[96]$} & Fast pyrolysis \\
1000 & Staw & 82 & 10.2 & 42.5 & 0.64 & {$[96]$} & Fast pyrolysis \\
900 & Wet wood & 46 & 9.9 & 34 & 0.50 & {$[183]$} & Fast pyrolysis \\
550 & Dry wood & 48.2 & 9.6 & 45 & 0.71 & {$[65]$} & Fast pyrolysis \\
400 & Wet wood & 14.3 & 8.80 & 36 & 1.02 & {$[116]$} & Fast pyrolysis \\
250 & Dry wood & 14 & 8.92 & 44 & 0.55 & {$[186]$} & Fast pyrolysis \\
200 & Wet wood & 8.8 & 4.84 & 36 & 1.11 & {$[116]$} & Fast pyrolysis \\
100 & Wet wood & 6.6 & 2.84 & 36 & 1.48 & {$[116]$} & Fast pyrolysis \\
24 & Rice husk & 3.89 & 0.170 & 22 & 0.82 & {$[180]$} & Fast pyrolysis \\
2.4 & Rice husk & 0.97 & 0.034 & 22 & 1.73 & {$[180]$} & Fast pyrolysis \\
\hline
\end{tabular}

Figure 11. Bio-oil production cost with plant sizes for wet wood pyrolysis.

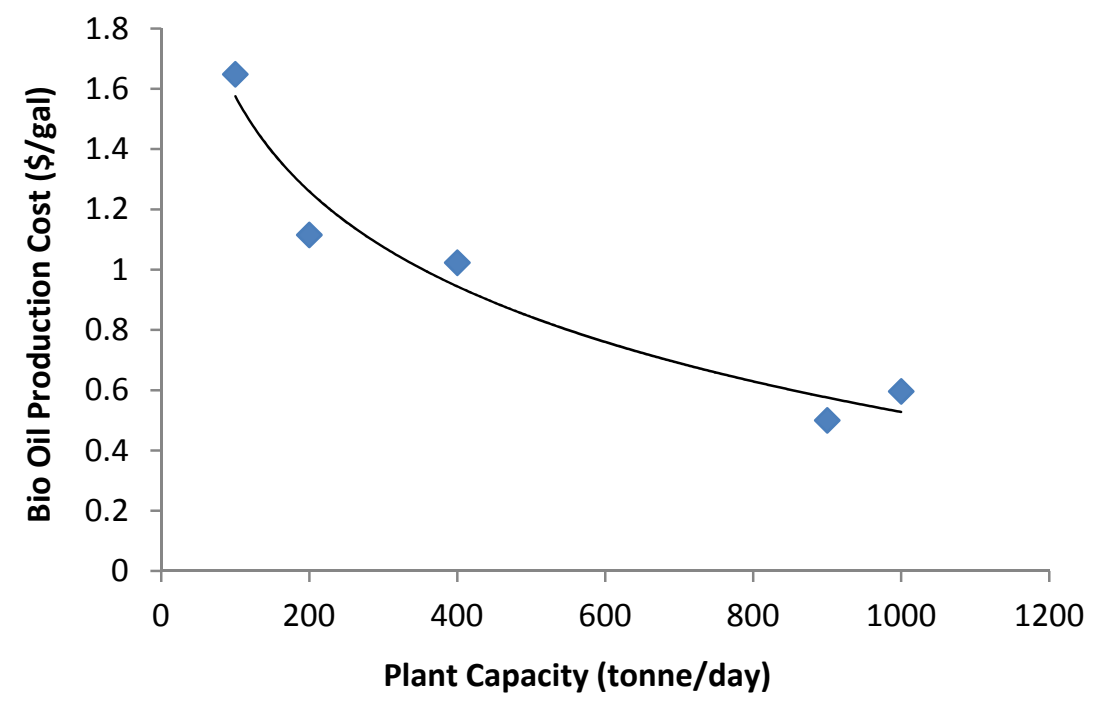

On the other hand, the concept of net present value (NPV) can used to evaluate the profitability of an investment. The NPV is today's value of current and future cash flows which can be given by $[187,188]$ :

$$
N P V=\sum_{n=1}^{T} \frac{C F_{n}}{(1+i)^{n}}-I_{0}
$$

where, $T$ is the life span of the investment (years), $\mathrm{CF}_{n}$ is the cash flow i.e. the difference between revenues and expenditures after tax in year $n, I_{0}$ is the expenditure connected with the initial 
investment in year zero, which means that the yearly cash flows $\mathrm{CF}_{n}$ (years $1, \ldots, n$ ) do not have to cover depreciation as such, and $i$ is the discount rate $(\%) . \mathrm{CF}_{n}$ can be calculated by:

$$
C F_{n}=(1-t) \times(R-E)+t \times D
$$

where, $t$ is the tax rate, $R$ is the revenue, $E$ is the expenditure and $D$ is the depreciation.

A detailed analysis and calculation of NPV can be found in Thewys and Kuppens [187] and in Voets et al. [188]. More techno-economic analysis and assessment of fast pyrolysis for power production can be found in [182,189,190]. More recently, Rogers and Brammer reviewed and compared the cost estimates of bio-oil production from Miscanthas and SRC (short rotation coppice) Willow through fast pyrolysis [191]. They estimated break even selling price (BESP) of bio-oil from Miscanthus for plant capacity of 50-800 tonne/day. They found that there is virtually no difference in production costs of bio-oil (i.e., BESP) for plant sizes more than 400 tonnes/day, and there was little difference in the processing cost for SRC willow and Miscanthus.

They mentioned that the BESP for the base case is not a realistic selling price, rather to be viable the selling price must cover possible risks and provide a profit to the operators. The operator's risk is any increase in cost that they are unlikely to be able to pass on to their customers. The risk event that had the highest BESP for a particular capacity of plant should be considered to be the minimum viable price for that plant. Although the bio-oil production cost as a function of plant capacity follows similar trend as shown in Figure 11, their estimated cost is higher than that shown in Figure 11 which could be due to the difference in assumptions and considerations (plant life, ash content, plant capacity factors, risk factors, feedstock price increase, operating cost increase, yield reduction, total plant costs, etc) used in the calculation. It is thus obvious that an in-depth study is needed for complete economic analysis (i.e., internal rate of return, payback period, life cycle cost analysis, etc) in order to assess its commercial viability. It is also to be noted that as the most of the above studies have focused on cost of bio-oil production, an economically defined feasible plant to date can still stays in risky enterprise. Therefore, the economic studies of pyrolysis plant should consider all pyrolysis products, namely gas, tar, char, chemicals and even ash.

\section{Discussion on Current Status of Pyrolysis Technology}

Many developing countries are continuing to use food crops like corn (maize), sugarcane, and soybean for generating biodiesel and ethanol which are unlikely to be sustainable for long periods [192,193]. Therefore extensive research is underway to develop processes with which biomass can be converted to hydrogen. Several other avenues are also being explored. But none of the options is economically feasible yet [194,195]. At present, great hope is pinned on high-yielding lignocellulosic biomass as a source of raw material for ethanol and other bio-fuels through pyrolysis processes [196]. But while the technology for conversion of food crops to ethanol is well established, the conversion of biomass to bio-oil through pyrolyis has still to overcome challenges. There is a need for better understanding of pyrolysis technology which can efficiently utilise biomass for large scale commercial production.

Among several fast pyrolysis companies reaching near-commercial status, Ensyn and DynaMotive have been dominating in North America since the 1990s. Both companies use renewable biomass, 
forest residues and agriculture wastes as the feedstock. DynaMotive emphasises the development and commercialisation of environmentally friendly energy systems based on fuels produced from biomass, while Ensyn commenced with an emphasises on the use of additional chemicals obtained from the process for food smoking and has since broadened into producing renewable fuel products from biomass [197,198]. Another two well-know pyrolysis bio-oil companies are Renewable Oil International and Pyrovac that basically use vacuum pyrolysis technology [199]. However there are many small and pilot scale pyrolysis bio-oil plants established and operated by different research organisations worldwide. Some of these are listed in Table 13.

Currently the main interests in pyrolysis technology are for electricity production from biomass, and $\mathrm{CO}_{2}$ mitigation, with socio-economic benefits from re-development of surplus agricultural land and energy independence being the driving forces. Although a number of installations were developed (Table 13), these are highly dependent on oil price, biomass availability and cost, local costs, labour etc. Most of the systems are used in pilot scale for research purpose while a few are being used in industrial processes where electricity, heat and steam are produced. Moreover researchers in recent time are paying more attention on maximising the overall oil yield from pyrolysis processes rather than paying sufficient attention to the product quality and upgrading of bio-oil.

Table 13. Worldwide current pyrolysis operating plants [65,79,182,200-203].

\begin{tabular}{cccc}
\hline Reactor Technology & Organisation/Location & $\begin{array}{c}\text { Capacity } \\
\text { (kg/h) }\end{array}$ & Desired Product \\
\hline Fixed bed & Bio-alternative, USA & 2000 & Char \\
Bubbling fluidised bed & THEE & 500 & Gas \\
& DynaMotive, Canada & 400 & Oil \\
& BEST Energy, Australia & 300 & Oil \\
& Wellman, UK & 250 & Oil \\
& Union Fenosa, Spain & 200 & Oil \\
& Zhejiang University, China & 20 & Oil \\
& RTI, Canada & 20 & Oil \\
& Waterloo university & 3 & Oil \\
Zirculating fluidised bed & Rejiang University, China & 3 & Oil \\
& Red Arrow, WI; Ensyn & 1700 & Chemicals \\
& Ensyn Engineering & 1500 & Chemicals \\
& VTT, Finland, Ensyn & 30 & Oil \\
Rotating cone & BTG, Netherlands & 20 & Oil \\
& University Twente & 10 & Oil \\
Vacuum & Pyrovac, Canada & 350 & Oil \\
& Laval University & 30 & Oil \\
Ablative & PYTEC, Gernamy & 250 & Oil \\
& BBC, Canada & $10-15$ & Oil \\
& PYTEC, Germany & 15 & Char \\
Vortex & Fortum, Finland & 30 & Oil \\
& University Zaragoza & 350 & Oil \\
& Georgia Tech. Research Ins. & 50 & Oil \\
& & Gas \\
& & Oil \\
\hline
\end{tabular}


It is evident from the from Table 13 that fluidised bed reactors are currently the most popular reactor in producing bio-oil from biomass through pyrolysis technology, followed by rotating cone, vacuum, ablative, vortex etc. However all types of reactor have technological advantages and shortcomings compared with each other. For an example, ablative pyrolysis is a process in which particles of biomass rub against the wall of a heated tube as they degrade; therefore this process is limited by the rate of heat supplied to the reactor. On the other hand the rate of heat absorption by the particles is better compared with fluid bed reactors. That means that larger biomass can be more practically processed by ablative reactors. A comprehensive study on advantages and limitations of different types of pyrolysis reactors has been conducted in this study and presented in Table 14. According to the findings of this study, the recommendations to achieve desired outputs from pyrolysis have been shown in Table 15.

Table 14. Advantages, disadvantages and bio-oil yield of different pyrolysis reactors [65,86,204-206].

\begin{tabular}{|c|c|c|c|}
\hline Reactor type & Advantages & Disadvantages & Bio-Oil Yield \\
\hline Fixed bed & $\begin{array}{l}\text { Simple design } \\
\text { Reliable } \\
\text { Biomass size independent }\end{array}$ & $\begin{array}{l}\text { High carbon conservation } \\
\text { Long solid residence time } \\
\text { Low ash carry over } \\
\text { Difficult to remove char }\end{array}$ & $35 \%-50 \%$ \\
\hline Bubbling fluidised bed & $\begin{array}{l}\text { Simple design } \\
\text { Easy operation } \\
\text { Good temperature control } \\
\text { Suitable for large scale } \\
\end{array}$ & Small particle sizes are needed & $70 \%-75 \%$ \\
\hline Circulating fluidised bed & $\begin{array}{l}\text { Well-understood technology } \\
\text { Good thermal control } \\
\text { Large particle sizes can be used }\end{array}$ & $\begin{array}{l}\text { Unlikely to be suitable for large } \\
\text { scale } \\
\text { Complex hydrodynamics } \\
\text { Char is finer }\end{array}$ & $70 \%-75 \%$ \\
\hline Rotating cone & $\begin{array}{l}\text { Centrifugal force moves heated sand } \\
\text { and biomass } \\
\text { No carrier gas required } \\
\text { Less wear }\end{array}$ & $\begin{array}{l}\text { Complex process } \\
\text { Small particle sizes needed } \\
\text { Not proven yet for large scale }\end{array}$ & $65 \%$ \\
\hline Vacuum & $\begin{array}{l}\text { Produces clean oil } \\
\text { Can process larger particles of } 3-5 \mathrm{~cm} \\
\text { No carrier gas required } \\
\text { Lower temperature required } \\
\text { Easier liquid product condensation }\end{array}$ & $\begin{array}{l}\text { Slow process } \\
\text { Solid residence time is too high } \\
\text { Require large scale equipment } \\
\text { Poor heat and mass transfer rate } \\
\text { Generates more water }\end{array}$ & $35 \%-50 \%$ \\
\hline Ablative & $\begin{array}{l}\text { Inert gas is not required } \\
\text { Large particle sizes can be processed } \\
\text { System is more intensive } \\
\text { Moderate temperature required }\end{array}$ & $\begin{array}{l}\text { Reactor is costly } \\
\text { Low reaction rate } \\
\text { Low reaction rate }\end{array}$ & $70 \%$ \\
\hline Auger & $\begin{array}{l}\text { Compact } \\
\text { No carrier gas required } \\
\text { Lower process temperature }\end{array}$ & $\begin{array}{l}\text { Moving parts in hot zone } \\
\text { Heat transfer in large scale is } \\
\text { not suitable }\end{array}$ & $30 \%-50 \%$ \\
\hline PyRos & $\begin{array}{l}\text { Compact and low cost } \\
\text { High heat transfer } \\
\text { Short gas residence time }\end{array}$ & $\begin{array}{l}\text { Complex design } \\
\text { Solids in the oil } \\
\text { Alkali dissolved in the oil } \\
\text { High temperature required }\end{array}$ & $70 \%-75 \%$ \\
\hline
\end{tabular}


Table 14. Cont.

\begin{tabular}{lllc}
\hline Reactor type & Advantages & Disadvantages & Bio-Oil Yield \\
\hline \multirow{3}{*}{ Plasma } & High energy density & $\begin{array}{l}\text { High electrical power } \\
\text { consumption }\end{array}$ & \\
& High heat transfer & High operating costs & $30 \%-40 \%$ \\
& High temperature & Small particle sizes required & \\
& Very good control & & \\
& Efficient heat transfer & & \\
& Exponential control & High electrical power & \\
& Compact & consumption & $60 \%-70 \%$ \\
Microwave & High heating rate & High operating costs & \\
& Large size biomass can be processed & & \\
& Uniform temperature distribution & & \multirow{2}{*}{$40 \%-60 \%$} \\
& High temperature & High costs & \\
\hline \multirow{5}{*}{ Solar } & Use renewable energy & Weather dependant & \\
& High heating rate & &
\end{tabular}

Table 15. Recommended pyrolysis technology according to product.

\begin{tabular}{lllllll}
\hline Product & $\begin{array}{l}\text { Pyrolysis } \\
\text { Type }\end{array}$ & Reactor & Heating Method & Temp. $\left({ }^{\circ} \mathbf{C}\right)$ & Biomass \\
\hline Bio-char & Slow & Fixed bed & Furnace or kilns & $<300$ & $\begin{array}{l}\text { Walnut shell, olive husk, } \\
\text { hazelnut shell }\end{array}$ \\
\hline Bio-oil & $\begin{array}{l}\text { Large } \\
\text { scale }\end{array}$ & Fast & $\begin{array}{l}\text { Bubbling } \\
\text { fluidised bed }\end{array}$ & Heated recycle gas & $450-550$ & $\begin{array}{l}\text { Agriculture residue, wood } \\
\text { chip, fruit shell }\end{array}$ \\
\cline { 2 - 7 } & $\begin{array}{l}\text { Medium } \\
\text { scale }\end{array}$ & Fast & $\begin{array}{l}\text { Circulating } \\
\text { fluidised bed }\end{array}$ & Wall and sand heating & $450-550$ & $\begin{array}{l}\text { Forest residue, municipal } \\
\text { waste, dry wood, waste } \\
\text { tyres }\end{array}$ \\
\cline { 2 - 7 } & $\begin{array}{l}\text { Small } \\
\text { scale }\end{array}$ & Flash & PyRos & PyRos heating & $450-550$ & Grass, husk, wood dust \\
\hline Syngas & & Slow/Fast & Microwave & Electromagnetic & $>800$ & Rice husk, wood dust \\
\hline
\end{tabular}

Very recently, Bridgewater reviewed emerging advanced technology of fast pyrolysis of biomass, both as an integrated process for production of liquid fuel, usually referred as bio-oil and as an intermediate pre-treatment step to convert solid biomass into energy content transportable liquid for subsequent processing for heat, power, biofuels and chemicals [207].

\section{Computational Fluid Dynamics Modeling of Pyrolysis Process}

Pyrolysis of biomass involves in producing a large number of intermediate and end products through numerous complex physical process and chemical reactions. Moreover, pyrolysis process is highly dependent on materials property variation including time dependent properties, temperature and pressure dependant properties, thermodynamic properties and dimensionless numbers. Therefore modeling and simulation could be the best possible option for understanding the thermochemical reaction mechanism, and also optimizing economic and efficient pyrolysis process design instead of having costly and time consuming experimental study. As a consequence numerous modeling works 
on pyrolysis have been carried out for last few decades dealing with a range of parameters including convective heat transfer [208], particle size, shape and orientation [209,210], vapor condensation [211], tar cracking, reactor temperature, heating rate [212], thermal conductivity and specific heat capacity of biomass [213], convective heat transfer coefficient of rectors and chemical kinetics [214]. However, computational fluid dynamics (CFD) is gaining more attention to use as virtual process engineering and identifying the most promising design of pyrolysis process as well as chemical reaction industries. Boateng and Mtui developed computational fluid dynamics (CFD) model in FLUENT-12 software to evaluate the pyrolysis products in a fluidized bed reactor for agricultural biomass [215]. While predicting the spontaneous emergence of pyrolysis vapors, char and non-condensable (permanent) gases, their model confirms that the kinetics are fast and that bio-oil vapor evolution is accomplished in a few seconds, and occupying two-thirds of the spatial volume of the reactor which is widely supported by different literature. Papadikis and Bridgwater analysed geometry of a $1 \mathrm{~kg} / \mathrm{h}$ bubbling fluidized bed reactor to improve certain hydrodynamic and gas flow characteristics using CFD model [216]. This study concluded that CFD can really aid the physical design of pyrolysis reactor by visualizing phenomena that would be otherwise left undetected by simple calculations. Papadikis et al. utilized CFD model in simulating the pyrolysis of single discrete biomass particles subjected to convective heat transfer for an entrained flow reactor (EFR) [217]. Likewise Brown et al. used CFD to predict an accurate time-temperature profile for the reactants and to understand the internal processes in a laminar entrained flow reactor [218]. In 2011 Brown et al. (2011) presented modelling and analysis for estimating profitability of two biochar production scenarios: slow pyrolysis vs fast pyrolysis [219]. Although, a large number of other studies have been carried out to simulate pyrolysis process using CFD, however most of them conducted analysis on fluidized bed reactors [216,220-222]. Those studies illustrated that; CFD models could be advantageous in the virtual design of fast pyrolysis reactors and optimising the design of reactor. At the same time experimental validation of these models is also very important which has largely been ignored in the past studies. The computational research will provide a clear understanding of the thermochemical process and its reaction mechanism and will allow upgrade and scale-up of existing rector technology. Further work should be done on CFD modelling and its experimental validation for different reactor geometry and operating conditions with wide range of biomass feedstock.

\section{Future Challenges}

Different applications of pyrolysis bio-oil are complex which is unlikely to be technically and economically feasible today. To achieve the potential of pyrolysis technology for bio-oil production from biomass, additional research and development are needed. Despite rapid development over the last few decades, commercialisation of pyrolysis bio-oil technology is still a long way off and needs to overcome many techno-economic barriers. Some of the important challenges for future pyrolysis research are listed below:

- Understand the trade-off between the size of the pyrolysis oil plant and feedstock and transportation costs to a centralized upgrading facility;

- Understand the limitations of the processes and where improvements can be made;

- Improvement of the reliability of pyrolysis reactors and processes; 
- Identify norms and quality standards of pyrolysis bio-oil for producers and users;

- Undertake in-depth life cycle energy and economic analyses of integrated pyrolysis plants;

- Encourage implementation processes and applications of pyrolysis products;

- Document environmental health and safety issues in handling, transport and usages;

- Improve the quality and consistency of bio-oil;

- Development of catalysts for bio-oil upgrading;

- Determine detailed characteristics of upgraded oil and other products;

- Development of more efficient technologies for the production of chemicals and biofuels from pyrolysis oils;

- Development of deoxygenated catalysts for pyrolysis processes to remove the oxygen containing compounds in the oil to improve the oil properties.

It is expected that, with the development of genetically engineered microorganisms capable of efficient pentose fermentation, ethanol production from hemicelluloses in biomass can be made more cost-effective [223,224]. An improvement in genetics, agronomy and the pyrolysis conversion process may help in the development of economically feasible bio-fuel production systems from biomass which will ensure more sophisticated bio-oil application in the near future.

\section{Conclusions and Recommendations}

Much attention has been given to biomass pyrolysis because of an opportunity for the processing of agricultural residues, wood wastes and municipal solid waste into clean energy. This study identified the route of pyrolysis technology i.e., selection of operating modes of pyrolysis, types of reactor, etc., based on the desired product output (bio-oil, bio-char or syngas). However, a sound understanding of the inherent process will allow pyrolysis products to be maximized. The following conclusion and recommendation could be drawn:

1. It is a research challenge to optimize the process by maximizing product quality and quantity while paying proper attention to minimizing costs and environmental concerns;

2. For fast pyrolysis, a wide range of different reactor configurations have been investigated. The most important reactor types are bubbling fluidized bed, circulating fluidized bed, rotating cone, ablative and entrained flow reactors. Among those, fluidizing bed reactors are the most popular types because of ease of operation, high stability under pyrolysis conditions and high oil yields;

3. Bio-oil production through pyrolysis is still an immature technology and is not commercially feasible yet. Pyrolysis bio-oil needs to overcome many technical, economic and social barriers to compete with tradition fossil fuels. Effective and rapid char separation techniques need to be developed so as to reduce solids contamination in bio-oil;

4. Along with pyrolysis technology, proper biomass selection is also a critical issue to achieve high bio-oil yields. Biomass with high cellulose content could be chosen, as bio-oils are mainly derived from it. In addition, biomass with low water content is desirable to reduce drying costs and improve oil quality; 
5. Modifications of engine, turbine and boiler combustion systems are required for proper utilization of pyrolysis bio-oil considering the effect of physical and chemical properties, gaseous and particle emissions, combustion efficiency, slag and carbon deposition and component material corrosion;

6. Numerous catalysts have been developed and tested to in pyrolysis process. Most of those were used only at small scale to improve gas production for research purposes having their own limitations. However sustainable industrial scale catalysts for biomass pyrolysis are yet to be identified;

7. Although a lot of studies have been conducted on pyrolysis economy but most of those were limited in small or pilot scale production. Detail economical assessment of industrial scale pyrolysis plant may be required to establish this technology as a competitor with conventional energy and other alternative energy sources;

8. Further study is recommended to address the issues mentioned above as well as the challenges outlined in Section 12.

\section{References}

1. Howarth, N.A.A.; Foxall, A. The Veil of Kyoto and the politics of greenhouse gas mitigation in Australia. Political Geogr. 2010, 29, 167-176.

2. Ramage, J.; Scurlock, J.; Biomass. In Renewable Energy-Power for a Sustainable Future; Boyle, G., Ed.; Oxford University Press: Oxford, UK, 1996.

3. Zhang, O.; Chang, J.; Wang, T.; Xu, Y. Review of biomass pyrolysis oil properties and upgrading research. Energy Convers. Manag. 2007, 48, 87-92.

4. Tsai, W.T.; Lee, M.K.; Chang, Y.M. Fast pyrolysis of rice husk: Product yields and compositions. Bioresour. Technol. 2007, 98, 22-28.

5. Bridgwater, A.V. Biomass fast pyrolysis. Therm. Sci. 2004, 8, 21-49.

6. Downie, A. BEST Pyrolysis Technology: A Solution for the Greenhouse Challenge. BEST Energies, Australia. ThermalNet Newsl. 2007, 5, 5.

7. Demirbas, A. Pyrolysis of ground beech wood in irregular heating rate conditions. J. Appl. Pyroyisis 2005, 73, 39-43.

8. Asadullah, M.; Rahman, M.A.; Ali, M.M.; Motin, M.A.; Sultan, M.B.; Alam, M.R. Production of bio-oil from fixed bed pyrolysis of bagasse. Fuel 2007, 86, 2514-2520.

9. Demiral, I.; Sensoz, S. The effects of different catalysts on the pyrolysis of industrial wastes (olive and hazelnut bagasse), Bioresour. Technol. 2008, 99, 8002-8007.

10. Mohan, D.; Pittman, C.U.; Bricka, M.; Smith, F.; Yancey, B.; Mohammad, J. Sorption of arsenic, cadmium, and lead by chars produced from fast pyrolysis of wood and bark during bio-oil production. J. Colloid Interf. Sci. 2007, 310, 57-73.

11. Aho, A.; Kumar, N.; Eranen, K.; Salmi, T.; Hupa, M.; Murzin, D.Y. Catalytic pyrolysis of woody biomass in a fluidized bed reactor: influence of the zeolite structure. Fuel 2008, 87, 2493-2501.

12. Karaosmanoglu, F.; Tetik, E. Fuel properties of pyrolytic oil of the straw and stalk of rape plant. Renew. Energy 1999, 16, 1090-1093. 
13. Jensen, P.A.; Sander, B.; Dam-Johansen, K. Pretreatment of straw for power production by pyrolysis and char wash. Biomass Bioenergy 2001, 20, 431-446.

14. Putun, E.; Uzun, B.B.; Putun, A.E. Fixed-bed catalytic pyrolysis of cotton-seed cake: Effects of pyrolysis temperature, natural zeolite content and sweeping gas flow rate. Bioresour. Technol. 2006, 97, 701-710.

15. Antal, M.J., Jr.; Grönli, M. The art, science, and technology of charcoal production. Ind. Eng. Chem. Res. 2003, 42, 1619-1640.

16. Mohan, D.; Pittman, C.U.; Steele, P.H. Pyrolysis of wood/biomass for bio-oil: A critical review. Energy Fuels 2006, 20, 848-889.

17. Demirbas, A. Partly chemical analysis of liquid fraction of flash pyrolysis products from biomass in the presence of sodium carbonate. Energy Convers. Manag. 2002, 43, 1801-1809.

18. Demirbas, A. The influence of temperature on the yields of compounds existing in bio-oils obtained from biomass samples via pyrolysis. Fuel Proc. Technol. 2007, 88, 591-597.

19. Demirbas, A. Combustion characteristics of different biomass fuels. Prog. Energy Combus. Sci. 2004, 30, 219-230.

20. Muradov, N.Z.; Veziroglu, T.N. "Green" path from fossil-based to hydrogen economy: An overview of carbon-neutral technologies, Int. J. Hydrog. Energy 2008, 33, 6804-6839.

21. Frassoldati, A.; Migliavacca, G.; Crippa, T.; Velata, F.; Faravelli, T.; Ranzi, E. Detailed Kinetic Modeling of Thermal Degradation of Biomasses. In Proceeding of the 29th Meeting on Combustion, Napoli, Italia, September 2006. Available online: ci.irc.na.cnr.it/download/ proc\%2006/documenti/Papers/09-02-frassoldati-039.pdf (accessed on 20 November 2012).

22. Pei-dong, Z.; Guomei, J.; Gang, W. Contribution to emission reduction of $\mathrm{CO}_{2}$ and $\mathrm{SO}_{2}$ by household biogas construction in rural China. Renew. Sustain. Energy Rev. 2007, 11, 1903-1912.

23. Thornley, P.; Upham, P.; Huang, Y.; Rezvani, S.; Brammer, J.; Rogers, J. Integrated assessment of bioelectricity technology options. Energy Policy 2009, 37, 890-903.

24. Somerville, C. Energy from Biomass; Workshop Presentration for the Inter Academy Council Study Report; Lighting the Way: Towards Sustainable Energy Future; IAC: Amsterdam, The Netherlands, 2005

25. Grønli, M.G.; Varhegyi, G.; Blassi, C.D. Thermogravimetric analysis and devolatilization kinetics of wood. Ind. Eng. Chem. Res. 2002, 41, 4201-4208.

26. Fisher, T.; Hajaligol, M.; Waymack, B.; Kellogg, D. Pyrolysis behaviour and kinetics of biomass derived materials. J. Appl. Pyrolysis 2002, 62, 331-349.

27. Lanzetta, M.; Blasi, D.C. Pyrolysis kinetics of wheat and corn straw. J. Anal. Appl. Pyrolysis. 1998, 44, 181-192.

28. Sinha, S.; Jhalani, A.; Ravi, M.R.; Ray, A. J. Solar Energy Soc. Ind. 2000, 10 , 41-62.

29. Venderbosch, R.H.; Prins, W. Review: Fast pyrolysis technology development. Biofuel 2010, 4, $178-208$.

30. International Energy Agency. Annual Report, 2006: IEA Bioenergy: Task 34, Pyrolysis of Biomass; International Energy Agency: Paris, France, 2006.

31. Balat, M.; Balat, M.; Kirtay, E.; Balat, H. Main routes for the thermo-conversion of biomass into fuels and chemicals. Part 1: Pyrolysis systems. Energy Conv. Manag. 2009, 50, 3147-3157.

32. Bridgwater, T. Pyrolysis of Biomass. IEA Bioenergy: Task 34; Bioenergy Research Group, Aston University: Birmingham, UK, 2007. 
33. Bridgwater, A.V.; Czernik, S.; Piskorz, J. An overview of fast pyrolysis. Prog. Thermochem. Biomass Convers. 2001, 2, 977-997.

34. Demirbas, A.H. Yields and heating values of liquids and chars from spruce trunkbark pyrolysis. Energy Source Part A 2005, 27, 1367-1373.

35. Tippayawong, N.; Kinorn, J.; Thavornun, S. Yields and gaseous composition from slow pyrolysis of refuse-derived fuels. Energy Source Part A 2008, 30, 1572-1578.

36. Demibas, A.; Arin, G. An overview of biomass pyrolysis. Energy Source Part A 2002, 24, 471-482.

37. Brammer, J.G.; Lauer, M.; Bridgwater, A.V. Opportunities for biomass-derived "bio-oil" in European heat and power markets. Energy Policy 2006, 34, 2871-2880.

38. Chiaramonti, D.; Oasmaa, A.; Solantausta, Y. Power generation using fast pyrolysis liquids from biomass. Renew. Sustain. Energy Rev. 2007, 11, 1056-1086.

39. Bridgwater, A.V. Fast Pyrolysis of Biomass: A Handbook; CRL Press: Newbury, UK, 2005.

40. Demirbas, A. Recent advances in biomass conversion technologies. Energy Educ. Sci. Technol. 2000, 6, 77-83.

41. Aguado, R.; Olazar, M.; Gaisan, B.; Prieto, R.; Bilbao, J. Kinetic study of polyolefin pyrolysis in a conical spouted bed reactor. Ind. Eng. Chem. Res. 2002, 41, 4559-4566.

42. Cornelissen, T.; Yperman, Y.; Reggers, G.; Schreurs, S.; Carleer, R. Flash co-pyrolysis of biomass with polylactic acid. Part 1: Influence on bio-oil yield and heating value. Fuel 2008, 87, 1031-1041.

43. Vamvuka, D.; Karakas, E.; Kastanaki, E.; Grammelis, P. Pyrolysis characteristics and kinetics of biomass residuals mixtures with lignite. Fuel 2003, 82, 1949-1960.

44. Goyal, H.B.; Seal, D.; Saxena, R.C. Bio-fuels from thermochemical conversion of renewable resources: A review. Renew. Sustain. Energy Rev. 2008, 12, 504-517.

45. McKendry, P. Energy production from biomass (part 1): Overview of biomass. Bioresour. Technol. 2002, 83, 37-46.

46. Twidell, J. Biomass energy. Renew. Energy World 1998, 3, 38-39.

47. Fegbemi, L.; Khezami, L.; Capart, R. Pyrolysis products from different biomasses: Application to the thermal cracking of tar. Appl. Energy 2001, 69, 293-306.

48. Yaman, S. Pyrolysis of biomass to produce fuels and chemical feedstocks. Energy Convers. Manag. 2004, 45, 651-671.

49. Gupta, A.K.; Lilley, D.G. Thermal destruction of wastes and plastics. In Plastics and the Environment; Andrady, A.L., Ed.; John Wiley \& Sons Ltd.: Chichester, UK, 2003; pp. 629-696.

50. Wang, G.; Li, W.; Li, B.; Chen, H. TG study on pyrolysis of biomass and its three components under syngas. Fuel 2008, 87, 552-558.

51. Yang, H.; Yan, R.; Chen, H.; Lee, D.H.; Liang, D.T.; Zheng, C. Pyrolysis of palm oil wastes for enhanced production of hydrogen rich gases. Fuel Proc. Technol. 2006, 87, 935-942.

52. Abbasi, T.; Abbasi, S.A. Biomass energy and the environmental impacts associated with its production and utilization. Renew. Sustain. Energy Rev. 2010, 14, 919-937.

53. Yang, H.; Yan, R.; Chen, H.; Lee, D.H.; Zheng, C. Characteristics of hemicellulose, cellulose and lignin pyrolysis. Fuel 2007, 86, 1781-1788. 
54. Wang, J.; Wang, G.; Zhang, M.; Chen, M.; Li, D.; Min, F.; Chen, M.; Zhang, S.; Ren, Z.; Yen, Y. A comparative study of thermolysis characteristic and kinetics of seaweeds and fir-wood. Proc. Biochem. 2006, 41, 1883-1886.

55. Fahmi, R.; Bridgwater, A.V.; Donnison, I.; Yates, N.; Jones, J.M. The effect of lignin and inorganic species in biomass on pyrolysis oil yields, quality and stability. Fuel 2008, 87, 1230-1240.

56. Demirbas, A. Current technologies for the thermo-conversion of biomass into fuels and chemicals. Energy Source Part A 2004, 26, 715-730.

57. Demirbas, A. Calculation of higher heating values of biomass fuels. Fuel 1997, 76, 431-434.

58. Yang, W.; Ponzio, A.; Lucas, C.; Blasiak, W. Performance analysis of a fixed-bed biomass gasifier using high-temperature air. Fuel Proc. Technol. 2006, 87, 235-245.

59. Gaunt, J.L.; Lehmann, J. Energy balance and emissions associated with biochar sequestration and pyrolysis bioenergy production. Environ. Sci. Technol. 2008, 42, 4152-4158.

60. Das, L.M.; Gulati, R.; Gupta, P.K. A comparative evaluation of the performance characteristics of a spark ignition engine using hydrogen and compressed natural gas as alternative fuels. Int. J. Hydrog. Energy 2000, 25, 783-793.

61. Blanco Lopez, M.C.; Blanco, C.G.; Martinez-Alonso, A.; Toscon, J.M.D. Composition of gases released during olive stones pyrolysis. J. Anal. Appl. Pyrolysis 2002, 65, 313-322.

62. Minkova, V.; Razvigorova, M.; Bjornbom, E.; Zanzi, R.; Budinova, T.; Petrov, N. Effect of water vapour and biomass nature on the yield and quality of the pyrolysis products from biomass. Fuel Proc. Technol. 2001, 70, 53-61.

63. Arni, S.A.; Bosio, B.; Arato, E. Syngas from sugarcane pyrolysis: An experimental study for fuel cell applications. Renew. Energy 2010, 35, 29-35.

64. Friedl, A.; Padouvas, E.; Rotter, H.; Varmuza, K. Prediction of heating values ofbiomass fuel from elemental composition. Anal. Chim. Acta 2005, 544, 191-198.

65. Ringer, M.; Putsche, V.; Scahill, J. Large-Scale Pyrolysis Oil Production and Economic Analysis; Technical Report NREL/TP-510-37779; National Renewable Energy Laboratory: Cole Boulevard, CO, USA, 2006.

66. Wang, X. Biomass Fast Pyrolysis in a Fluidized Bed. Ph.D. Thesis, University of Twente, Enscheda, The Netherlands, 2006.

67. Wang, X.; Kersten, S.R.A.; Prins, W.; Van Swaaij, W.P.M. Biomass pyrolysis in a fluidized bed reactor. Part 2: Experimental Validation of Model Results. Ind. Eng. Chem. Res. 2005, 44, 8786-8795.

68. A Review of fixed bed gasification systems for biomass. Agric. Eng. Int. 2007, 5, 1-23.

69. Altafini, C.R.; Wander, P.R.; Barreto, R.M. Prediction of the working parameters of a wood waste gasifier through an equilibrium model. Energy Convers. Manag. 2003, 44, 2763-2777.

70. Leung, D.Y.C.; Yin, X.L.; Wu, C.Z. A review on the development and commercialization of biomass gasification technologies in China. Renew. Sustain. Energy Rev. 2004, 8, 565-580.

71. Barker, S.N. Gasification and pyrolysis-routes to competitive electricity production in the UK. Energy Convers. Manag. 1996, 37, 861-866.

72. Filippis, P.D.; Borgianni, C.; Paolucci, M.; Pochetti, F. Gasification process of Cuban bagasse in a two-stage reactor. Biomass Bioenergy 2004, 27, 247-252. 
73. Rao, M.S.; Singha, S.P.; Sodhaa, M.S.; Dubey, A.K.; Shyam, M. Stoichiometric, mass, energy and exergy balance analysis of countercurrent fixed-bed gasification of post-consumer residues. Biomass Bioenergy 2004, 27, 155-171.

74. Pathak, B.S. Biomass to power rural development. In Proceedings of National Seminar on Biomass Based Decentralized Power Generation; Pathak, B.S., Ed.; Sardar Patel Renewable Energy Research Institute: Vallabh Vidyanagar, India, 2005; pp. 1-6.

75. Lv, P.M.; Xiong, Z.H.; Chang, J.; Wu, C.Z.; Chen, Y.; Zhu, J.X. An experimental study on biomass air-steam gasification in a fluidized bed. Bioresour. Technol. 2004, 95, 95-101.

76. Sadaka, S.; Boateng, A.A. Pyrolysis and Bio-Oil, Agriculture and Natural Resources; FSA1052; University of Arkansas: Fayetteville, AK, USA. Available online: http://www.uaex.edu/ Other_Areas/publications/PDF/FSA-1052.pdf (accessed on 5 August 2010).

77. Li, X.T.; Grace, R.; Lim, C.J.; Watkinson, A.P.; Chen, H.P.; Kim, J.R. Biomass gasification in a circulating fluidized bed. Biomass Bioenergy 2004, 26, 171-193.

78. Jones, S.B.; Holladay, J.E.; Valkenburg, C.; Stevens, D.J.; Walton, C.W.; Kinchin, C.; Elliott, D.C.; Czernik, S. Production of Gasoline and Diesel from Biomass via Fast Pyrolysis, Hydrotreating and Hydrocracking: A Design Case; Report No. PNNL-18284; U.S. Department of Energy: Springfield, VA, USA, 2009.

79. FAO. The Research Progress of Biomass Pyrolysis Processes; National Resource Management Environment Department: Available online: www.fao.org/docrep (accessed on 14 June 2010).

80. Roy, C.; Blanchette, D.; Korving, L.; Yang, J.; DeCaumia, B. Development of a Novel Vacuum Pyrolysis Reactor with Improved Heat Transfer Potential. In Developments in Thermochemical. Biomass Conversion; Bridgewater, A.V., Boocock, D.G.B., Eds.; Blackie Academic and Professional: London, UK 1997; pp. 351-367.

81. Wagenaar, B.M.; Venderbosch, R.H.; Carrasco, J.; Strenziok, R.; Van der Aa, B.J. Rotating Cone Bio-oil Production and Applications. In Progress in Thermochemical. Biomass Conversion; Bridgewater, A.V., Ed.; Blackwell Science: Oxford, UK, 2001; pp. 1268-1280.

82. Bramer, E.A.; Holthuis, M.R. Clean Liquid Fuel through Flash Pyrolysis. In The Development of the PyRos Process; AFTUR Final Report; University of Twente: Enschede, The Netherlands, 2005.

83. Tang, L.; Huang, H. Plasma pyrolysis of biomass for production of syngas and carbon adsorbent. Energy Fuels 2005, 19, 1174-1178.

84. Chen, G.; Andries, K.; Luo, Z.; Spliethoff, H. Biomass pyrolysis/Gasification for product gas production. The overall investigation of parametric effects. Energy Convers. Manag. 2003, 44, 1873-1884.

85. Fernández, Y.; Menéndez, J.A. Influence of feed characteristics on the microwave-assisted pyrolysis used to produce syngas from biomass wastes.J. Anal. Appl. Pyrolysis 2011, 91, 316-322.

86. Lam, S.S.; Russell, A.D.; Chase, H.A. Microwave pyrolysis, a novel process for recycling waste automotive engine oil. Energy 2010, 35, 2985-2991.

87. Domínguez, A.; Fernández, Y.; Fidalgo, B.; Pis, J.J.; Menéndez, J.A. Bio-syngasproduction with low concentration of $\mathrm{CO}_{2}$ and $\mathrm{CH}_{4}$ from microwave-induced pyrolysis of wet and dried sewage sludge. Chemosphere 2008, 70, 397-403. 
88. Domínguez, A.; Menéndez, J.A.; Fernández, Y.; Pis, J.J.; Valente Nabais, J.M.; Carrott, P.J.M.; Ribeiro Carrott, M.M.L. Conventional and microwave induced pyrolysis of coffee hulls for the production of a hydrogen rich fuel gas. J. Anal. Appl. Pyrolysis 2007, 79, 128-135.

89. Fernández, Y.; Arenillas, M.A.; Díez, P.J.J.; Menéndez, J.A. Pyrolysis of glycerol over activated carbons for syngas production. J. Anal. Appl. Pyrolysis 2009, 84, 145-150.

90. Huang, Y.F.; Kuan, W.H.; Lo, S.L.; Lin, C.F. Total recovery of resources and energy from rice straw using microwave-induced pyrolysis. Bioresour. Technol. 2008, 99, 8252-8258.

91. Zhao, X.; Song, Z.; Liu, H.; Li, Z.; Li, L.; Ma, C. Microwave pyrolysis of corn stalk bale: A promising method for direct utilization of large-sized biomass and syngas production. J. Anal. Appl. Pyrolysis 2010, 89, 87-94.

92. Chen, J.; Zhu, D.; Sun, C. Effect of heavy metals on the sorption of hydrophobic organic compounds to wood charcoal. Environ. Sci. Technol. 2007, 41, 2536-2541.

93. Boutin, O.; Ferrer, M.; Lede, J. Flash pyrolysis of cellulose pellets submitted to a concentrated radiation: experiments and modeling. Chem. Eng. Sci. 2002, 57, 15-25.

94. Hofmann, L.; Antal, M.J. Numerical simulations of the performance of solar fired flash pyrolysis reactors. Sol. Energy 1984, 33, 427-440.

95. Shakya, B.D. Pyrolysis of Waste Plastics to Generate Useful Fuel Containing Hydrogen Using a Solar Thermo-Chemical Process. Ph.D. Thesis, School of Chemical and Biomolecular Engineering, University of Sydney, Sydney, Australia, 2007.

96. Solantausta, Y.; Oasmaa, A. Fast Pyrolysis of Forestry Residues and Sawdust, Production and Fuel Oil Quality. In Proceedings of International Nordic Bioenergy Conference, Javaskyla, Frinland, September 2003; pp. 1-3.

97. Oasmaa, A.; Kuoppala, E. Fast pyrolysis of forestry residue. 3. Storage stability of liquid fuel. Energy Fuel 2003, 17, 1075-1084.

98. Czernik, S.; Bridgwater, A.V. Applications of biomass fast pyrolysis oil. Energy Fuel 2004, 18, 590-598.

99. Siemons, R.V. Bio-oil production from biomass: The pyrolysis process. Available online: http://www.cleanfuels.nl/Projects\%20\&\%20publications/CFUL\%20pyrolysis.pdf (accessed on 20 November 2012).

100. Dobele, G.; Urbanovich, I.; Volpert, A.; Kampars, V.; Samulis, E. Fast pyrolysis-Effect of wood drying on the yield and properties of bio-oil. BioResources 2007, 2, 699-706.

101. Sharma, R.K.; Wooten, J.B.; Baliga, V.L.; Lin, X.; Chan, W.G.; Hajaligol, M.R. Characterization of chars from pyrolysis of lignin. Fuel 2004, 83, 1469-1482.

102. Wang, X.; Cents, A.H.G.; Kersten, S.R.A.; Prins, W.; Van Swaaij, W.P.M. A Filter-Assisted Fluid Bed Reactor for Integrated Production and Clean-Up of Bio-Oil. In Proceedings of the 2nd World Conference on Bioenergy, Rome, Italy, 10-14 May 2004.

103. Scahill, J.; Diebold, J.P.; Feek, C. Removal of Residual Char Fines from Pyrolysis Vapors by Hot Gas Filtration. In Developments in Thermochemical Biomass Conversion; Blackie Academic \& Professional: London, UK, 1997; pp. 253-266.

104. Bramer, E.A.; Holthis, M.R.; Brem, G. Development of a Cyclonic Reactor with Internal Particle Filter for the Flash Pyrolysis of Biomass; the PyRos Reactor. In Proceedings of the $2^{\text {nd }}$ World Conference on Bioenergy, Rome, Italy, 10-14 May 2004. 
105. Johnson, W.L.; Yavari, G.H.; Radelin, D.; St. A, G. Apparatus for Separating Fouling Contaminants from Non-Condensable Gases at the End of Pyrolysis/Thermolysis of Biomass Process. US Patent 7,004,999 B2, 2006.

106. Demirbas, A. Production of gasoline and diesel fuels from bio-materials. Energy Source Part A 2007, 29, 753-760.

107. Demirbas, A. Mechanisms of liquefaction and pyrolysis reactions of biomass. Energy Convers. Manag. 2000, 41, 633-646.

108. Bridgwater, A.V.; Czernik, S.; Diebold, J. Fast Pyrolysis of Biomass: A Handbook; CRL Press: London, UK, 1999.

109. Diebold, J. A Review of the Chemical and Physical Mechanisms of the Storage and Stability of Fast Pyrolysis Bio-Oils; NREL 1; Thermalchemie, Inc.: Lakewood, CO, USA, 2000.

110. Evans, R.; Milne, T. Molecular characterisation of the pyrolysis of biomass 1. Energy Fuel 1987, $1,123-137$.

111. Oasmaa, A.; Meier, D. Norms and standards for fast pyrolysis liquids: 1. Round robin test. J. Anal. Appl. Pyrolysis 2005, 73, 323-334.

112. Shihadeh, A.; Hochgreb, S. Diesel engine combustion of biomass pyrolysis oils. Energy Fuels 2000, 14, 260-274.

113. Abdullah, N. An Assessment of Pyrolysis for Processing Empty Fruit Bunches. Ph.D. Thesis, Aston University, Birmingham, UK, 2005.

114. Fahmi, R.; Bridgwater, A.; Thain, V.S.; Donnison, I. Prediction of Klason lignin and lignin thermal degradation products by Py-GC/MS in a collection of Lolium. and Festuca. grasses. J. Anal. Appl. Pyrolysis 2007, 80, 16-23.

115. Sensoz, S.; Angin, D. Pyrolysis of safflower (Charthamus tinctorius L.) seed press cake in a fixed-bed reactor: Part 2. Structural characterization of pyrolysis bio-oils. Bio-Resour. Technol. 2008, 99, 5498-5504.

116. Mullaney, H.; Farag, I.H.; LaClaire, C.L.; Barrett, C.J. Technical, Environmental and Economic Feasibility of Bio-Oil in New Hampshire's North Country; Final Report; New Hampshire Industrial Research Center (NHIRC): Durham City, NH, USA, 2002.

117. Freel, B.A.; Graham, R.G.; Huffman, D.R. Commercial Aspects of Rapid Thermal Processing (RTMTM). In Bio-Oil Production and Utilization; CPL Press: Newbery, UK, 1996; pp. 86-95.

118. Gust, S. Combustion Experiences of Flash Pyrolysis Fuel in Intermediate Size Boilers. In Developments in Thermochemical Biomass Conversion; Bridgwater, A.V., Boocock, D.G., Eds.; Blackie Academic \& Professional: London, UK, 1997; pp. 481-488.

119. Oasmaa, A.; Kytö, M.; Sipilä, K.; Pyrolysis Oil Combustion Tests in an Industrial Boiler. In Progress in Thermochemical Biomass Conversion; Blackwell Science: Oxford, UK, 2001; pp. 1468-1481.

120. Agarwal, A.K. Biofuels (alcohols and biodiesel) applications as fuels for internal combustion engines. Prog. Energy Combust. Sci. 2007, 33, 233-271.

121. Labeckas, G.; Slavinskas, S. Performance of direct-injection off-road diesel engine on rapeseed oil. Renew. Energy 2006, 31, 849-863.

122. Ramadhas, A.S.; Jayaraj, S.; Muraleedharan, C. Characterization and effect of using rubber seed oil as fuel in the compression ignition engines. Renew. Energy 2005, 30, 795-803. 
123. Jayed, M.H.; Masjuki, H.H.; Saidur, R.; Kalam, M.A.; Jahirul, M.I. Environmental Aspects and Challenges of Oilseed Produced Biodiesel in Southeast Asia. Renew. Sustain. Energy Rev. 2009, 13, 2452-2462.

124. Solantausta, Y.; Beckman, D.; Bridgwater, A.V.; Diebold, J.P.; Ellioit, D.C. Assessment of Liquefaction and Pyrolysis Systems. Biomass Bioenergy 1994, 2, 279-297.

125. Chiaramonti, D.; Bonini, M.; Fratini, E.; Tondi, G.; Gartner, K.; Bridgwater, A.V.; Grimm, H.P.; Soldaini, I.; Webster, A.; Baglioni, P. Development of Emulsions from Biomass Pyrolysis Liquid and Diesel and Their Use in Engines. Biomass Bioenergy 2003, 25, 101-111.

126. Baglioni, P.; Chiaramonti, D.; Bonini, M.; Soldaini, I.; Tondi, G. Bio-Crude-Oil/Diesel Oil Emulsification: Main Achievements of the Emulsification Process and Preliminary Results of Tests on Diesel Engine. In Progress in Thermochemical Biomass Conversion; Blackwell Science: Oxford, UK, 2001; pp. 1525-1539.

127. Ormrod, D.; Webster, A. Progress in Utilization of Bio-Oil in Diesel Engines. In PyNe News Letter; Aston University: Birmingham, UK, 2000; p. 15.

128. Strenziok, R.; Hansen, U.; Künster, H. Combustion of Bio-Oil in a Gas Turbine. In Progress in Thermochemical Biomass Conversion; Blackwell Science: Oxford, UK, 2001; pp. 1452-1458.

129. Hague, R.A. The Pre-Treatment and Pyrolysing of Biomass for the Production of Liquids for Fuel and Speciality Chemicals. Ph.D Thesis, Aston University, Birmingham, UK, 1998.

130. Rocha, J.D.; Olivares-Gómez, E.; Mesa-Pérez, J.M.; Cortez, L.A.B.; Seye, O.; Brossard-González, L.E. The demonstration fast pyrolysis plant to biomass conversion in Brazil. In Proceedings of World Renewable Energy Congress VII (WRC 2002), Cologne, Germany, 2002.

131. González, J.F.; Román, S.; Encinar, J.M.; Martinéz, G. Pyrolysis of various biomass residues and char utilization for the production of activated carbons. J. Anal. Appl. Pyrolysis 2009, 85, 134-141.

132. Downie, A.; Crosky, A.; Munroe, P. Physical Properties of Biochar. In Biochar for Environmental Management: Science and Technology; Lehmann, J., Joseph, S., Eds.; Earthscan: London, UK, 2009

133. Brown, R. Biochar Production Technology. In Biochar for Environmental Management: Science and Technology; Lehmann, J., Joseph, S., Eds.; Earthscan: London, UK, 2009.

134. Cetin, E.; Moghtaderi, B.; Gupta, R.; Wall, T.F. Influence of pyrolysis conditions on the structure and gasification reactivity of biomass chars. Fuel 2004, 83, 2139-2150.

135. Lua, A.C.; Yang, T.; Guo, J. Effects of pyrolysis conditions on the properties of activated carbons prepared from pistachio-nut shells. J. Anal. Appl. Pyrolysis 2004, 72, 279-287.

136. Dawei, A.; Zhimin, W. Shuting, Z.; Hongxing, Y. Low-temperature pyrolysis of municipal solid waste: Influence of pyrolysis temperature on the characteristics of solid fuel. Int. J. Energy Res. 2006, 30, 349-357.

137. Sohi, S.; Lopez-Capel, E.; Krull, E.; Bol, R. Biochar, Climate Change and Soil: A Review to Guide Future Research; CSIRO Land and Water Science Report; CSIRO: Canberra, Australia, 2009.

138. Verheijen, F.; Jeffery, S.; Bastos, A.C.; van der Velde, M.; Diafas, I. Biochar Application to Soils: A Critical Scientific Review of Effects on Soil Properties, Processes and Functions; European Commission Report No. EUR 24099 EN; European Communities, Ispara, Italy, 2010. 
139. Bourke, J.; Manley-Harris, M.; Fushimi, C.; Dowaki, K.; Nunoura, T.; Antal, M.J., Jr. Do all carbonised charcoals have the same structure? A model of the chemical structure of carbonized charcoal. Ind. Eng. Chem. Res. 2007, 46, 5954-5967.

140. Van Zwieten, L.; Kimber, S.; Morris, S.; Chan, K.Y.; Downie, A.; Rust, J.; Joseph, S.; Cowie, A. Effects of biochar from slow pyrolysis of papermill waste on agronomic performance and soil fertility. Plant. Soil 2009, 1-12.

141. Amonette, J.E.; Jospeh, S. Characteristics of Biochar: Microchemical Properties. In Biochar for Environmental Management Science and Technology; Lehmann, J., Joseph, S., Eds.; Earthscan: London, UK, 2009.

142. Gaskin, J.W.; Steiner, C.; Harris, K.; Das, K.C.; Bibens, B. Effect of low-temperature pyrolysis conditions on biochar for agricultural use. Trans. ASABE 2008, 51, 2061-2069.

143. Kantarelis, E.; Zabaniotou, A. Valorization of cotton stalks by fast pyrolysis and fixed bed air gasification for syngas production as precursor of second generation biofuels and sustainable agriculture. Bioresour. Technol. 2009, 100, 942-947.

144. He, M.; Xiao, B.; Liu, S.; Hu, Z.; Guo, X.; Luo, S. Syngas production from pyrolysis of municipal solid waste (MSW) with dolomite as downstream catalysts. J. Anal. Appl. Pyrolysis 2010, 87, 181-187.

145. Wei, L.; Thomasson, J.A.; Bricka, R.M.; Batchelor, W.D.; Columbus, E.P.; Wooten, J.R. Experimental Study of a Downdraft Gratifier; ASABE Meeting Paper No. 066029; American Society of Agricultural and Biological Engineers: St. Joseph, Michigan, 2006.

146. Ahmed, I.; Gupta, A.K.; Syngas yield during pyrolysis and steam gasification of paper. Appl. Energy 2009, 86, 1813-1821.

147. Dasappa, S.; Paul, P.J.; Mukunda, H.S.; Rajan, G.N.K.; Sridhar, S.; Sridhar, H.V. Biomass gasification technology-A route to meet energy needs. Curr. Sci. 2004, 87, 908-916.

148. Couher, C.; Commandre, J.M.; Salvador, S. Failure of the component additivity rule to predict gas yields of biomass in flash pyrolysis at $950^{\circ} \mathrm{C}$. Biomass Bioenergy 2009, 33, 316-326.

149. Couher, C.; Commandre, J.M.; Salvador, S. Is it possible to predict gas yields of any biomass after rapid pyrolysis at high temperature from its composition in cellulose, hemicelluloses and lignin? Fuel 2009, 88, 408-417.

150. Jahirul, M.I.; Masjuki, H.H.; Saidur, R.; Kalam, M.A.; Jayed, M.H.; Wazed, M.A. Comparative Engine performance and Emission Analysis of CNG and Gasoline in a Retrofitted Car Engine. Appl. Ther. Eng. 2010, 30, 2219-2226.

151. Kahraman, E.; Ozcanli, S.C.; Ozerdem, B. An experimental study on performance and emission characteristics of a hydrogen fuelled spark ignition engine. Int. J. Hydrog. Energy 2007, 32, 2066-2072.

152. Saidur, R.; Jahirul, M.I.; Moutushi, T.Z.; Imtiaz, H.; Masjuki, H.H. Effect of partial substitution of diesel by natural gas on performance parameters of a four cylinder diesel engine. Proceedings of the Institution of Mechanical Engineers, UK. J. Power Energy Part A 2007, 221, 1-10.

153. Shah, A.; Srinivasan, R.; To, S.D.F.; Columbus, E.P. Performance and emissions of a spark-ignited engine driven generator on biomass based syngas. Bioresour. Technol. 2010, 101, 4656-4661. 
154. Mustafi, N.N.; Miragliab, Y.C.; Rainea, R.R.; Bansala, P.K.; Elder, S.T. Spark-ignition engine performance with "Powergas" fuel (mixture of $\mathrm{CO} / \mathrm{H}_{2}$ ): A comparison with gasoline and natural gas. Fuel 2006, 85, 1605-1612.

155. Papagiannakis, R.G.; Rakopoulos, C.D.; Hountalas, D.T.; Giakoumis, E.G. Study of the performance and exhaust emissions of a spark-ignited engine operating on syngas fuel. Int. J. Alter. Propuls. 2007, 2, 190-215.

156. McMillian, M.H.; Lawson, S.A. Experimental and modeling study of hydrogen/syngas production and particulate emissions from a natural gas-fueled partial oxidation engine. Int. Hydrog. Energy 2006, 31, 847-860.

157. Shudo, T.; Nagano, T.; Kobayashi, M. Combustion characteristics of waste pyrolysis gases in an internal combustion engine. Int. J. Automot. Technol. 2003, 4, 1-8.

158. Sobyanin, V.; Sadykov, V.; Kirillov, V.; Kuzmin, V.; Kuzin, N.; Vostrikov, Z.; Khristolyubov, A.; Luksho, V.; Afanasiev, A. Syngas as a Fuel for IC and Diesel Engines: Efficiency and Harmful Emissions Cut-off. In Proceedings of International Hydrogen Energy Congress and Exhibition, Istanbul, Turkey, 13-15 July 2005.

159. Ahmad, I.; Gupta, A.K. Pyrolysis and gasification of food waste: Syngas characteristics and char gasification kinetics. Appl. Energy 2010, 87, 101-108.

160. He, M.; Hu, Z.; Xiao, B.; Li, J.; Guo, X.; Luo, S.; Yang, F.; Feng, Y.; Yang, G.; Liu, S. Hydrogen-rich gas from catalytic steam gasification of municipal solid waste (MSW): Influence of catalyst and temperature on yield and product composition. Int. J. Hydrog. Energy 2009, 34, 195-203.

161. Hao, X.H.; Guo, L.J.; Mao, X.; Zhang, X.M.; Chen, X.J. Hydrogen production from glucose used as a model compound of biomass gasified in supercritical water. Int. J. Hydrog. Energy 2003, 28, 55-64.

162. Han, J.; Kim, H. The reduction and control technology of tar during biomass gasification/pyrolysis: An overview. Renew. Sustain. Energy Rev. 2008, 12, 397-416.

163. Hu, G.; Xu, S.P.; Li, S.G.; Xiao, C.G.; Liu, S.Q. Steam gasification of apricot stones with olivine and dolomite as downstream catalysts, Fuel Process. Technol. 2006, 87, 375-382.

164. Xiao, B.; Wang, Y.Y.; Su, Q. The research of treating municipal solid waste by gasification. China Resour. Compr. Utilization 2006, 24, 18-20.

165. Chaudhari, S.T.; Dalai, A.K.; Bakhshi, N.N. Production of hydrogen and/or syngas $\left(\mathrm{H}_{2}+\mathrm{CO}\right)$ via steam gasification of biomass-derived chars. Energy Fuels 2003, 17, 1062-1067.

166. Gallucci, K.; Stendardo, S.; Foscolo, P.U. $\mathrm{CO}_{2}$ capture by means of dolomite in hydrogen production. Int. J. Hydrog. Energy 2008, 33, 3049-3055.

167. Mahishi, M.R.; Goswami, D.Y. An experimental study of hydrogen production by gasification of biomass in the presence of a $\mathrm{CO}_{2}$ sorbent. Int. J. Hydrog. Energy 2007, 32, 2803-2808.

168. Wei, L.; Xu, S.P.; Zhang, L.; Liu, C.H.; Zhu, H.; Liu, S.Q. Steam gasification of biomass for hydrogen-rich gas in a free-fall reactor, Int. J. Hydrog. Energy 2007, 32, $24-31$.

169. Xiaodong, Z. The Mechanism of Tar Cracking by Catalyst and the Gasification of Biomass. Ph.D Thesis, Zhejiang University, Zejiang, China, 2003.

170. Elbaba, I.F.; Wu, C.; Williams, P.T. Hydrogen production from the pyrolysis-gasification of waste tyres with a nickel/cerium catalyst. Int. J. Hydrog. Energy 2011, 36, 6628-6637. 
171. Ates, F.M.; Isikdag, M.A. Influence of temperature and alumina catalyst on pyrolysis of corncob, Fuel 2009, 88, 1991-1997.

172. Tomishinge, K.; Asadullah, M.; Kunimori, K. Syngas production by biomass gasification using $\mathrm{Rh} / \mathrm{CeO} / \mathrm{SiO}_{2}$ catalysts and fluidized bed reactor. Catal. Today 2004, 89, 389-403.

173. Iwaki, H.; Ye, S.; Katagiri, H.; Kitagawa, K. Wastepaper gasification with $\mathrm{CO}_{2}$ or steam using catalysts of molten carbonates. Appl. Catal. A: Gen. 2004, 270, 237-243.

174. Demirbas, A. Gaseous products from biomass by pyrolysis and gasification: Effects of catalyst on hydrogen yield. J. Energy Convers. Manag. 2002, 43, 897-909.

175. Wang, P.; Tanabe, E.; Ito, K.; Jiab, J.; Morioka, H.; Shishido, T.; Takehira, K. Filamentous carbon prepared by the catalytic pyrolysis of $\mathrm{CH}_{4}$ on $\mathrm{Ni} / \mathrm{SiO}_{2}$. Appl. Catal. A: Gen. 2002, 231, 35-44.

176. Williams, P.T.; Alexander, J. Catalytic pyrolysis of tyres: Influence of catalyst temperature. Fuel 2002, 81, 2425-2434.

177. Watanabe, M.; Inomata, H.; Arai, K. Catalytic hydrogen generation from biomass (glucose and cellulose) with $\mathrm{ZrO}_{2}$ in supercritical water. Biomass Bioenergy 2002, 22, 405-410.

178. Stals, M.; Carleer, R.; Reggers, G.; Schreurs, S.; Yperman, J. Flash pyrolysis of heavy metal contaminated hardwoods from phytoremediation: Characterisation of biomass, pyrolysis oil and char/ash fraction. J. Anal. Appl. Pyrolysis 2010, 89, 22-29.

179. Thornley, P.; Wright, E. Evaluation of Bio-Energy Projects. In PyNe Final Report to the EC; European Commission: Brussels, Belgium, 2001.

180. Islam, M.N.; Ani, F.N. Techno-economics of rice husk pyrolysis, conversion with catalytic treatment to produce liquid fuel. Bisour. Technol. 2000, 73, 67-75.

181. Polagye, L.B.; Hodgson, K.T.; Malte, P.C. An economic analysis of bio-energy options using thinnings from overstocked forests. Biomass Bioenergy 2007, 31, 105-125.

182. Wright, M.M.; Daugaard, D.E.; Satrio, J.A.; Brown, R.C. Techno-economic analysis of biomass fast pyrolys to transportation fuels. Fuel 2010, 89, S2-S10.

183. Luo, Z.; Wang, S.; Liao, Y.; Zhou, J.; Gu, Y.; Cen, K. Research on biomass fast pyrolysis for liquid fuel. Biomass Bioenergy 2004, 26, 455-462.

184. Gregoire, C.E.; Bain, R.L. Technoeconomic analysis of the production of biocrude from wood. Biomass Bioenergy 1994, 7, 275-283.

185. Cottam, M.L.; Bridgwater, A.V. Techno-economic modeling of biomass flash pyrolysis and upgrading systems. Biomass Bioenergy 1994, 7, 267-273.

186. Gregoire, C.E. Technoeconomic Analysis of the Production of Biocrude from Wood; NREL/TP-430-5435; National Renewable Energy Laboratory: Golden, CO, USA, 1992.

187. Thewys, T.; Kuppens, T. Economics of willow pyrolysis after phytoextraction. Int. J. Phytoremediat. 2008, 10, 561-583.

188. Voets, T.; Kuppens, T. Economics of electricity and heat production by gasification or flash pyrolysis of short rotation coppice in Flanders (Belgium). Biomass Bioenergy 2011, 35, 1912-1924.

189. Bridgwater, A.V.; Toft, A.J. A techno-economic comparison of power production by biomass fast pyrolysis with gasification and combustion. Renew. Sustain. Energy Rev. 2002, 6, 181-248. 
190. Peacocke, G.V.C.; Bridgwater, A.V. Techno-Economic Assessment of Power Production from the Wellman and btg Fast Pyrolysis Processes. In Science in Thermal and Chemical Biomass Conversion; Bridgwater, A.V., Boocock, D.G., Eds.; CPL Press: Birmingham, UK, 1785.

191. Rogers, J.G.; Brammer, J.G. Estimation of the production cost of fast pyrolysis bio-oil. Biomass Bioenergy 2012, 36, 208-217.

192. Lora, E.S.; Andrade, R.V. Biomass as energy source in Brazil. Renew. Sustain. Energy Rev. 2009, 13, 777-788.

193. Demirbas, M.F.; Balat, M.; Balat, H. Potential contribution of biomass to the sustainable energy development. Energy Convers. Manag. 2009, 50, 1746-1760.

194. Yu, S.; Tao, J. Simulation-based life cycle assessment of energy efficiency of biomass-based ethanol fuel from different feedstocks in China. Energy 2009, 34,476-484.

195. Saxena, R.C.; Adhikari, D.K.; Goyal, H.B. Biomass-based energy fuel through biochemical routes. Renew. Sustain. Energy Rev. 2009, 13, 167-178.

196. Hill, J. Environmental costs and benefits of transportation biofuel production from food- and lignocelluloses-based energy crops. Agron. Sustain. Devel. 2007, 27, 1-12.

197. Homepage of DynaMotive Energy Systems Corporation. Available online: http://www.dynamotive.com (accessed on 15 September 2010).

198. Homepage of Ensyn Group Inc. Available online: http://www.ensyn.com (accessed on 10 June 2011).

199. Homepage of Renewable Oil International. Available online: http://www.renewableoil.com (accessed on 12 October 2011).

200. PYTEC. Bio-Fuel Based on Agricultural and Forest Residues-The Alternative Renewable Energy of Our Future; PYTEC: Northampton, UK, 2005.

201. Meier, D. New Ablative Pyrolyzer in Operation in GERMANY. Available online: http://www.pyne.co.uk/Resources/user/PYNE\%20Newsletters/PyNews\%2017.pdf (accessed on 20 November 2012).

202. Boulard, D.C. Bio-Oil; The New Crude. Presented at Ensyn RTP ${ }^{\mathrm{TM}}$ Bio-Refinary: Bio-oil Briefing session, Concord, NH, USA, 16 August 2002.

203. Brown, D.B. Continuous ablative regenerator system. In Proceedings of the 2nd EU-Canada Workshop on Thermal Biomass Processing; Bridgwater, A.V., Hogan, E.N., Eds.; CPL Press: Newbury, UK, 1996; pp. 96-100.

204. Menendez, J.A.; Dominguez, A.; Inguanzo, M.; Pis, J.J. Microwave pyrolysis of sewage sludge: Analysis of the gas fraction. J. Appl. Pyrolysis 2004, 71, 657-667.

205. Zhao, X.; Hunang, H.; Wu, C.; Li, H.; Chen, Y. Biomass pyrolysis in an Argon/Hydrogen plasma reactor. Chem. Eng. Technol. 2001, 24, 197-199.

206. Scott, D.S.; Majerski, P.; Piskorz, J.; Radlein, D. A second look at fast pyrolysis of biomass - The RTI process. J. Anal. Appl. Pyrolysis 1999, 51, 23-37.

207. Bridgwater, A.V. Review of fast pyrolysis of biomass and product upgrading. Biomass Bioenergy 2012, 38, 68-94.

208. Moghtaderi, B. The state-of-the-art in pyrolysis modelling of lignocellulosic solid fuels. Fire Mater. 2006, 30, 1-34.

209. Papadikis, K.; Gu, S.; Bridgwater, A.V. A CFD approach on the effect of particle size on char entrainment in bubbling fluidised bed reactors. Biomass Bioenergy 2010, 34, 21-29. 
210. Babu, B.V.; Chaurasia, A.S. Dominant design variables in pyrolysis of biomass particles of different geometries in thermally thick regime. Chem. Eng. Sci. 2004, 59, 611-622.

211. Papadikis, K.; Gu, S.; Bridgwater, A.V. Eulerian model for the condensation of pyrolysis vapors in a water condenser. Energy Fuels 2011, 25, 1859-1868.

212. Babu, B.V.; Chaurasia, A.S. Modeling, simulation and estimation of optimum parameters in pyrolysis of biomass. Energy Convers. Manag. 2003, 44, 2135-2158.

213. Tanoue, K.-I.; Hinauchi, T.; Oo, T.; Nishimura, T.; Taniguchi, M.; Sasauchi, K.-I. Modeling of heterogeneous chemical reactions caused in pyrolysis of biomass particles. Adv. Powder Technol. 2007, 18, 825-840.

214. Thunman, H.; Leckner, B. Thermal conductivity of wood-Models for different stages of combustion. Biomass Bioenergy 2002, 23, 47-54.

215. Boateng, A.A.; Mtui, P.L. CFD modeling of space-time evolution of fast pyrolysis products in a bench-scale fluidized-bed reactor. Appl. Ther. Eng. 2012, 33-34.

216. Papadikis, K.; Gu, S.; Bridgwater, A.V. 3D simulation of the effects of sphericity on char entrainment in fluidised beds. Fuel Proc. Technol. 2010, 91, 749-758.

217. Papadikis, K.; Gu, S.; Bridgwater, A.V.; Gerhauser, H. Application of CFD to model fast pyrolysis of biomass. Fuel Proc. Technol. 2009, 90, 504-512.

218. Brown, A.L.; Dayton, D.C.; Nimlos, M.R.; Daily, J.W. Design and characterization of an entrained flow reactor for the study of biomass pyrolysis chemistry at high heating rates. Energy Fuels 2001, 15, 1276-1285.

219. Brown, T.R.; Wright, M.M.; Brown, R.C. Estimating profitability of two biochar production scenarios: slow pyrolysis vs. fast pyrolysis. Biofuels Bioprod. Bioref. 2011, 5, 54-68.

220. Papadikis, K.; Gu, S.; Bridgwater, A.V. Computational modelling of the impact of particle size to the heat transfer coefficient between biomass particles and a fluidised bed. Fuel Proc. Technol. 2010, 91, 68-79.

221. Yuen, R.K.K.; Yeoh, G.H.; Davis, D.V.; Leonardi, E. Modelling the pyrolysis of wet wood-I. Three-dimensional formulation and analysis. Int. J. Heat Mass Transfer 2007, 50, 4371-4386.

222. Yuen, R.K.K.; Yeoh, G.H.; Davis, D.V.; Leonardi, E. Modelling the pyrolysis of wet wood-II. Three-dimensional cone calorimeter simulation. Int. J. Heat Mass Transfer 2007, 50, 4387-4399.

223. Hoekman, S.K. Biofuels in the U.S.-Challenges and opportunities. Renew. Energy 2009, 34, 14-22.

224. Sarath, G.; Mitchell, R.B.; Sattler, S.E.; Funnell, D.; Pedersen, J.F.; Graybosch, R.A.; Vogel, K.P. Opportunities and roadblocks in utilizing forages and small grains for liquid fuels. J. Ind. Microbiol. Biotechnol. 2008, 35, 343-354.

(C) 2012 by the authors; licensee MDPI, Basel, Switzerland. This article is an open access article distributed under the terms and conditions of the Creative Commons Attribution license (http://creativecommons.org/licenses/by/3.0/). 